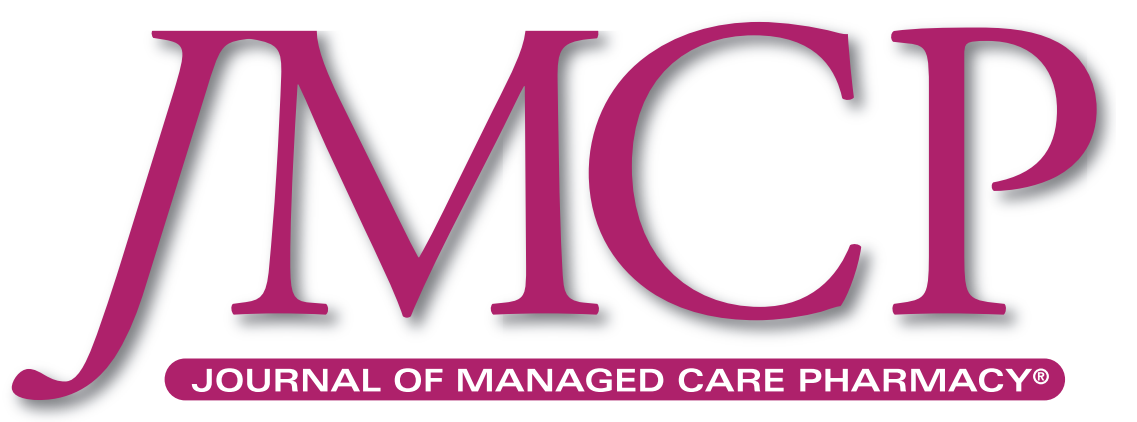

\title{
Viscosupplementation: \\ Managed Care Issues for Osteoarthritis of the Knee
}

William Arnold, MD; Dwight S. "Pete" Fullerton, PhD, PRh;

Sharon Holder, MSN, APRN, NP-C; and Coral S. May, RN, BSN, CME, MP

\section{Supplement \\ May 2007}

Vol. 13, No. 4

Continuing Education Program 


\section{JMCP}

Editor-in-Chief

Frederic R. Curtiss, PhD, RPh, CEBS

(830) 935-4319, fcurtiss@amcp.org

Managing Editor

Tamara C. Faggen, (703) 323-0170

tfaggen@amcp.org

\section{Assistant Editor}

Diane P. Britton

drbritton@verizon.net

Peer Review Administrator

Jennifer A. Booker, (703) 317-0725

jmcpreview@amcp.org

Graphic Designer

Laura J. Mahoney, (703) 944-4577

lauramahoney@comcast.net

\section{Account Manager}

Peter Palmer, (856) 795-5777, ext. 13

peter@promedgroup.net

\section{Publisher}

Judith A. Cahill, CEBS

Executive Director

Academy of Managed Care Pharmacy

This supplement to the Journal of Managed Care Pharmacy. (ISSN 1083-4087) is a publication of the Academy of Managed Care Pharmacy, 100 North Pitt St., Suite 400, Alexandria, VA 22314; (703) 683-8416; (703) 683-8417 (fax).

Copyright $\odot$ 2007, Academy of Managed Care Pharmacy. All rights reserved. No part of this publication may be reproduced or transmitted in any form or by any means, electronic or mechanical, without written permission from the Academy of Managed Care Pharmacy.

POSTMASTER: Send address changes to JMCP,

100 North Pitt St., Suite 400, Alexandria, VA 22314.

\section{Supplement Policy Statement Standards for Supplements to the Journal of Managed Care Pharmacy}

Supplements to the Journal of Managed Care Pharmacy are intended to support medical education and research in areas of clinical practice, health care quality improvement, or efficient administration and delivery of health benefits. The following standards are applied to all JMCP supplements to assure quality and assist readers in evaluating potential bias and determining alternate explanations for findings and results.

1. Disclose the principal sources of funding in a manner that permits easy recognition by the reader.

2. Disclose the existence of all potential conflicts of interest among supplement contributors, including financial or personal bias.

3. Describe all drugs by generic name unless the use of the brand name is necessary to reduce the opportunity for confusion among readers.

4. Strive to report subjects of current interest to managed care pharmacists and other managed care professionals.

5. Seek and publish content that does not duplicate content in the Journal of Managed Care Pharmacy.

6. Subject all supplements to expert peer review.
William Arnold, MD, FACP, FACR, is a rheumatologist at the Illinois Bone \& Joint Institute, Morton Grove, Illinois, and medical director of Advanced Bio-Surfaces, Inc., Minnetonka, Minnesota. He is past chair of the Department of Medicine, Lutheran General Hospital, Park Ridge, Illinois. His clinical research interests include patient care and research in the medical, biological, and minimally invasive surgical treatment of arthritis. Arnold earned his medical degree from the University of Illinois College of Medicine and completed both a residency in internal medicine and a fellowship in rheumatology at Duke University Medical Center.

Dwight S. "Pete" Fullerton, PhD, PRh, is a professor (affiliate) at the University of Washington Pharmaceutical Outcomes Research and Policy Program, Seattle. As president of Strategic Pharmacy Innovations, he works as a health care consultant for government, the pharmaceutical industry, and health insurance carriers. He has been a member of the Board of Directors of the International Society of Pharmacoeconomics and Outcomes Research (ISPOR) and currently is cochair of the ISPOR Managed Care Special Interest group. He is also a member of the Editorial Advisory Board of Value in Health. Fullerton, Sean Sullivan, Debbie Atherly, and Dell Mather started the formulary submission process that has now been adopted as the national standard by the Academy of Managed Care Pharmacy. He received a doctorate from the University of California, Berkeley, and bachelor of science degrees in pharmacy and chemistry from Oregon State University.

Sharon Holder, MSN, APRN, NP-C, is a rheumatology nurse practitioner with the Ochsner Clinic Foundation, Baton Rouge, Louisiana, where she provides direct care to patients with musculoskeletal disorders. She is certified as a registered nurse and an advanced practice registered nurse with the Louisiana State Board of Nursing and as an adult nurse practitioner through the American Academy of Nurse Practitioners. She also serves on the board of directors for the Arthritis Association of Louisiana and is a member of the Association of Rheumatology Health Professionals and the American Academy of Nurse Practitioners. Holder received her master of nursing and adult acute-care practitioner certificate from the University of South Alabama.

Coral S. May, RN, BSN, CME, MP, is president and founder (health behavior change strategist) of e3 COMMUNICATION, Fort Worth, Texas. She has broad experience encompassing health care consulting, worksite-based health management program design and implementation, training for health care professionals, managed care, management, and marketing. May is credentialed as a certified menopause educator through the National Certification Corporation and as a menopause practitioner through the North American Menopause Society. She received her bachelor of science in nursing from the University of the Incarnate Word and will receive her master of health care administration from the University of Texas at Arlington in August 2007 


\title{
Table of Contents
}

\section{Viscosupplementation: Managed Care Issues for Osteoarthritis of the Knee}

S3 Viscosupplementation: Managed Care Issues for Osteoarthritis of the Knee William Arnold, MD; Dwight S. "Pete" Fullerton, PhD, PRh; Sharon Holder, MSN, APRN, NP-C; and Coral S. May, RN, BSN, CME, MP

S20 Continuing Education Posttest, Posttest Answers, Program Evaluation, and Verification of Completion Forms

\begin{abstract}
Purpose
Provide the latest information on therapeutic options for $\mathrm{OA}$ of the knee, including viscosupplementation

Target Audience

Physicians, nurses, pharmacists, and case managers who treat patients with osteoarthritis

\section{Learning Objectives}

Upon completion of this activity, participants will be better able to

1. explain the pathophysiologic factors involved in osteoarthritis $(\mathrm{OA})$ of the knee,

2. describe appropriate treatment for patients with $\mathrm{OA}$ of the knee, and

3. discuss benefits of viscosupplementation for management of $\mathrm{OA}$ of the knee as they pertain to the managed care environment.
\end{abstract}

This supplement was funded through an educational grant from Genzyme Biosurgery and is based on the proceedings of a series of meetings that took place in a managed care setting. It is jointly sponsored by Postgraduate Institute for Medicine (PIM) and Excellence in Medical Education (XME).

The opinions expressed in the educational activity are those of the faculty and do not necessarily represent the official policies or views of the Academy of Managed Care Pharmacy, the authors' institutions, PIM, XME, and Genzyme Biosurgery.

\section{Disclosure of Unlabeled Use}

This educational activity may contain discussion of published and/or investigational uses of agents that are not indicated by the U.S. Food and Drug Administration. PIM, XME, and Genzyme Biosurgery do not recommend the use of any agent outside of the labeled indications. Please refer to the official prescribing information for each product for discussion of approved indications, contraindications, and warnings.

\section{Disclaimer}

Participants have an implied responsibility to use the newly acquired information to enhance patient outcomes and their own professional development. The information presented in this activity is not meant to serve as a guideline for patient management. Any procedures, medications, or other courses of diagnosis or treatment discussed or suggested in this activity should not be used by clinicians without evaluation of their patients' conditions and possible contraindications on dangers in use, review of any applicable manufacturer's product information, and comparison with recommendations of other authorities, applicable manufacturer's product information, and comparison with recommendations of other authorities. 


\section{Viscosupplementation: Managed Care Issues for Osteoarthritis of the Knee}

\section{Method of Participation}

There are no fees for participating and receiving CE or CME credit for this activity. During the period from May 1, 2007 (release date), through May 31, 2008 (expiration date), participants must (1) read the learning objectives and faculty disclosures, (2) study the educational activity, (3) complete the posttest by recording the best answer to each question in the answer section of the Posttest Answers form, (4) complete the Program Evaluation form, and (5) mail or fax the Posttest Answers and Program Evaluation forms to Postgraduate Institute for Medicine (PIM). To complete this activity online, please see page S2O.

The estimated time to complete this activity is 1 hour and 25 minutes. A statement of credit will be issued only upon receipt of a completed activity evaluation form and a completed posttest with a score of $70 \%$ or better. Your statement of credit will be mailed to you within 3 weeks.

\section{Physician:}

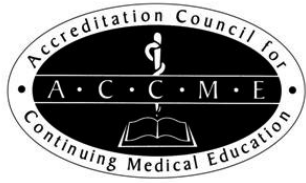

\section{Accreditation statement:}

This activity has been planned and implemented in accordance with the Essential Areas and Policies of the Accreditation Council for Continuing Medical Education (ACCME) through the joint sponsorship of Postgraduate Institute for Medicine (PIM) and Excellence in Medical Education (XME). PIM is accredited by ACCME to provide continuing medical education for physicians.

Credit designation:

PIM designates this educational activity for a maximum of 1.25 AMA PRA Category 1 Credits $^{\mathrm{TM}}$. Physicians should only claim credit commensurate with the extent of their participation in the activity.

(Media: journal supplement)

\section{Pharmacist:}

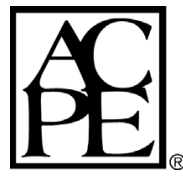

\section{Accreditation statement:}

Postgraduate Institute for Medicine (PIM) is accredited by the Accreditation Council for Pharmacy Education (ACPE) as a provider of continuing pharmacy education.

\section{Credit designation:}

PIM designates this continuing education activity for 0.11 CEUs ( 1.1 contact hours).

ACPE Universal Program No. 809-999-07-048-H01.

\section{Nurse: \\ CNA/ANCC}

This educational activity for 1.1 contact hours is provided by Postgraduate Institute for Medicine (PIM).

PIM is an approved provider of continuing nursing education by the Colorado Nurses Association, an accredited approver by the American Nurses Credentialing Center's Commission on Accreditation.

\section{Disclosure of Conflicts of Interest}

Postgraduate Institute for Medicine (PIM) assesses conflict of interest with its instructors, planners, managers and other individuals who are in a position to control the content of CME activities. All relevant conflicts of interest that are identified are thoroughly vetted by PIM for fair balance, scientific objectivity of studies utilized in this activity, and patient care recommendations. PIM is committed to providing its learners with high-quality CME activities and related materials that promote improvements or quality in health care and not a specific proprietary business interest or a commercial interest.

\section{Auhtor/Reviewer Disclosures}

The authors received honoraria from Genzyme Biosurgery for their participation in the meetings on which this supplement is based. The authors disclose the following: William Arnold has received consulting fees from Genzyme Biosurgery and contracted research with Abbott, Genzyme, Merck, Pfizer, and TAP Pharmaceuticals; Dwight S. "Pete" Fullerton has prepared AMCP dossiers for Genzyme; Sharon Holder and Coral S. May disclose no significant financial relationship with any commercial entity related to this activity. The following PIM clinical content reviewers, Jan Hixon, RN, Linda Graham, RN, and Trace Hutchison, PharmD, and XME content reviewer, Danielle Seaberg, PharmD, disclose that they do not have any financial relationships or relationships to products or devices with any commercial interests related to the content of this CME activity. 


\title{
Viscosupplementation: Managed Care Issues for Osteoarthritis of the Knee
}

\author{
William Arnold, MD; Dwight S. "Pete" Fullerton, PhD, RPh; \\ Sharon Holder, MSN, APRN, NP-C; and Coral S. May, RN, BSN, CME, MP
}

\begin{abstract}
BACKGROUND: 0steoarthritis (OA) affects an estimated 49 million adults in North America, or nearly 1 of every 6 adults. More than 8 million North Americans have limited mobility to some extent because of $\mathrm{OA}$. By 2030, an estimated 71 million North Americans will be diagnosed with $\mathrm{OA}$, an increase of $45 \%$ over current figures. For one group-model health maintenance organization (HMO), the average cost of care for patients with $0 \mathrm{~A}$ was $\$ 543$ per member, a total annual cost to the HMO of $\$ 4,728,425$. Of this total amount, $46 \%$ was for inpatient care, $32 \%$ was for medication, and $22 \%$ was for ambulatory care.
\end{abstract}

OBJECTIVE: To determine the impact of OA on managed care and discuss treatment options available to those with $\mathrm{OA}$, particularly of the knee.

SUMMARY: OA represents an advanced stage of an active, progressive disease process. We know from medical research that $\mathrm{OA}$ is the endpoint of a progression in tissue degradation that results in loss of cartilage structure and function. Relief of pain and preservation of joint tissue must evolve to encompass treatments that interfere with cartilage-degrading mechanisms that follow acute or chronic injury, restore normal cartilage and joint homeostasis, and arrest the progression of disease. Optimal future treatments will also reverse existing damage and restore normal cartilage structure and function.

Viscosupplementation with an elastoviscous fluid containing polymers of hylan derivatives of the natural glycosaminoglycan hyaluronan is indicated for treating pain of $\mathrm{OA}$ of the knee that has not responded to or is contraindicated for conservative nonpharmacologic therapy and traditional analgesics. These analgesics include acetaminophen, nonsteroidal anti-inflammatory drugs (NSAIDs), and cyclooxygenase-2 (COX-2) inhibitors.

Clinicians in the managed care setting may consider using viscosupplementation in patients (1) who have persistent pain despite their use of conservative nonpharmacologic and pharmacologic therapy (e.g., exercise, weight loss, physician therapy, bracing/orthotics, NSAIDs, COX-2 inhibitors, and intra-articular glucocorticoids); (2) who have compromised gastrointestinal (GI) function or who are at risk for Gl bleeding due to the adverse events of NSAIDs; (3) who are taking concomitant anticoagulant therapy for any condition; (4) who have cardiovascular or renal risk factors that preclude use of COX-2 inhibitors; and (5) for whom surgery is not appropriate.

Further study should be conducted with larger numbers of patients to help identify a subgroup of patients with $O A$ in whom viscosupplementation may have even greater effects. Additional research should also concentrate on assessing the risks and benefits of extended treatments, because limited data are available concerning the effectiveness of multiple courses of therapy.

CONCLUSION: OA is an important public health issue as the leading cause of disability in North America. As populations age, socioeconomic costs of $\mathrm{OA}$ will dramatically increase. Among available treatment options, viscosupplementation is a valuable alternative to more conservative therapy and has the benefit of circumventing the possible side effects of systemically administered pharmacologic agents. Viscosupplementation demonstrated efficacy in $\mathrm{OA}$ of the knee, and its use in the managed care arena may generate savings in hospitalizations and other costs.

KEYWORDS: Cartilage-degrading mechanisms, Cost-effectiveness, Hyaluronan, Haluronate, Hylan, Managed care, Osteoarthritis, Viscosupplementation

J Manag Care Pharm. 2007;13(4)(suppl):S3-S19
$\mathrm{O}$ steoarthritis (OA) of the knee is a prevalent and often incapacitating condition that can be treated in a variety of ways, resulting in a range of clinical outcomes. This article will provide a brief overview of $\mathrm{OA}$ and specifically of $\mathrm{OA}$ of the knee. A concise review of the epidemiology, pathophysiology, and diagnostic tools associated with these conditions follows. Treatment options approved by the U.S. Food and Drug Administration (FDA) will be reviewed, with a focus on viscosupplementation. Pertinent cost-effectiveness data on treatment options for OA of the knee also will be presented.

\section{General Overview of Osteoarthritis}

$\mathrm{OA}$, the most common joint disorder, is a chronic arthropathy of 1 or more joints characterized by degeneration and loss of joint cartilage, along with other joint changes, including bone hypertrophy. ${ }^{1}$ A progressive disease that occurs mainly in the latter half of life, OA can be progressively disabling. Patients mainly seek medical care because of the intractable pain caused by OA. ${ }^{2}$ It often becomes symptomatic in the fifth and sixth decades of life and is almost universal by age $80 .{ }^{1}$ In individuals younger than 40 years, $\mathrm{OA}$ occurs more frequently in men and is primarily a result of trauma. Occurrence predominates in women from age 40 to 70 years, after which men and women are equally affected.

\section{Impact}

The estimated total cost associated with $\mathrm{OA}$, including medical care and lost productivity costs, exceeds $\$ 86.2$ billion. ${ }^{3} \mathrm{OA}$ is the leading cause of lost time from work. ${ }^{3}$ In addition, patients incur higher age-adjusted medical costs than do those without $\mathrm{OA}$, not only for arthritis care but also for the care of comorbidities in the neurologic, gastrointestinal (GI), cardiovascular, and respiratory systems, to which patients may be more susceptible because of

Authors

WILLIAM ARNOLD, MD, is a rheumatologist, Illinois Bone and Joint Institute, Ltd., Morton Grove, Illinois; DWIGHT S. "PETE" FULLERTON, PhD, RPh, is a professor (affiliate), University of Washington, Pharmaceutical Outcomes Research and Policy Program, Seattle, and president, Strategic Pharmacy Innovations, Seattle; SHARON HOLDER, MSN, APRN, NP-C, is a rheumatology nurse practitioner, Oschner Health Center, Baton Rouge, Louisiana; CORAL S. MAY, RN, BSN, CME, MP, is president and founder, e3 COMMUNICATION, Fort Worth, Texas

AUTHOR CORRESPONDENCE: William Arnold, MD, Illinois Bone and Joint Institute, Ltd., 9000 Waukegan Rd., Morton Grove, IL 60053 Tel: (847) 375-3000; Fax: (847) 853-0515; E-mail:billncele@comcast.net

Copyright $\odot$ 2007, Academy of Managed Care Pharmacy. All rights reserved. 


\section{TABLE 1 Demographics of Osteoarthritis (OA) of the Knee in the United States}

- Prevalence: >13.5 million American adults report having knee joint pain, swelling, and stiffness ${ }^{50}$

- Age and duration: mean age of patients is 66 years, and mean symptom duration is 8 years ${ }^{25}$

- Race/ethnicity: the prevalence of knee OA among white persons is approximately twice that of black persons ${ }^{25}$

- Medical visits:

- Patients make >5.5 million visits to physician offices and >271,000 outpatient visits ${ }^{50}$

- In 1999, >400,000 inpatient hospital stays were reported for persons with OA of the knee $^{49}$

- Average duration of stay: almost 5 days

- Average charge per hospital stay: $\$ 23,746$

- Upon release, about $20 \%$ of patients with knee OA enter a skilled nursing facility or nursing home

- In 1999, about $25 \%$ of patients with knee OA underwent surgery, most often total knee replacement

- Patient self-report of general health: $>40 \%$ of people with knee OA rate their health as "fair" or "poor"

- Impact on function: Approximately 50\% of patients with knee OA have difficulty crouching, stooping, or kneeling ${ }^{1}$

overall decline in health. ${ }^{3}$ Because of the high prevalence of OA and the associated medical costs, OA greatly impacts managed care. For one group-model health maintenance organization (HMO), the average cost of care for patients with OA was $\$ 543$ per member per year, at a total annual cost to the HMO of $\$ 4,728,425$. Of this total amount, $46 \%$ was for inpatient care, $32 \%$ was for medication, and $22 \%$ was for ambulatory care. ${ }^{4}$

\section{Pathophysiology and Pathogenesis}

The pathogenesis and pathophysiology of $\mathrm{OA}$ is complex and affects several systems, beginning with the articular cartilage, which is a complex material synthesized and maintained by its living component, the chondrocyte. ${ }^{5}$ Water makes up $65 \%$ to $85 \%$ of cartilage and interacts with matrix proteoglycans, matrix collagens, hyaluronic acid, and other components. Healthy cartilage is balanced between matrix synthesis and matrix degradation. In OA, regardless of the involved joint, matrix degradation overtakes matrix synthesis.

Articular cartilage degradation is associated with abnormal joint stresses over time. Stresses include obesity, which can place an abnormal load on the knee joint, microfractures in the subchondral bone, and trauma. Concurrent factors, including normal aging, metabolic diseases, inflammation, and immune system malfunctions, lead to biochemical changes that also result in cartilage degradation. These work synergistically to compromise cartilage, which results in (1) biophysical changes, such as collagen network fracture and proteoglycan unraveling, and (2) biochemical changes, such as a reduction in inhibitors of degradative enzymes and an increase in proteolytic enzymes. $\mathrm{OA}$ is the endpoint of this series of events. ${ }^{5}$

All joint tissues become involved in OA. Subchondral bone stiffens and then undergoes infarction, becomes osteoporotic, and develops subchondral cysts. ${ }^{1}$ Attempts at bony repair produce subchondral sclerosis; efforts to stabilize the joint produce osteophytes at the joint margins. Inflammation and thickening of the synovium ensues, producing more copious synovium. Periarticular tendons and ligaments become strained, resulting in tendonitis and contractures. As the joint becomes less mobile, surrounding muscles thin and become less supportive.

These mechanisms are gradual, and the patient most often describes a deep aching pain as the earliest symptom. Therefore, $\mathrm{OA}$ begins as a disease of a single tissue with a single etiology and eventually becomes a disease of an organ (synovial joint), in which cartilage is primarily affected but which ultimately involves all tissues: bone, synovium, muscle, capsule, ligaments, and cartilage. ${ }^{1}$

The pathways that contribute to the pain of $\mathrm{OA}$ can be complex. Pain can be classified as (1) nociceptive, which occurs as a result of tissue damage activating nociceptors in either peripheral or deep tissues and is considered protective; (2) inflammatory, which can follow an inflammatory response to tissue damage and is a component of nociceptive pain; (3) neuropathic, which results from direct injury to nerves; and/or (4) functional, which is associated with an absence of neurologic deficit or peripheral abnormality. ${ }^{6}$ In most cases of chronic pain, several pain pathways tend to coexist.

\section{The Role of Hyaluronic Acid}

Normal articular cartilage is composed of an extracellular matrix and chondrocytes, the cells that produce and maintain the cartilage. ${ }^{7}$ Within the matrix, water, collagen fibers, and proteoglycan macromolecules_large molecules containing protein and a type of polysaccharide-are cross-linked into an integrated network. The backbone of each proteoglycan network is a large molecule of hyaluronic acid, also called hyaluronan or sodium hyaluronate. ${ }^{5}$ The interaction of these molecules forms the structural network providing cartilage with its most important biomechanical properties, compressibility and elasticity. ${ }^{5}$

High concentrations of hyaluronic acid are also found in the synovial fluid. ${ }^{8}$ In healthy joints, this highly viscous, shockabsorbing lubricant is contained within the joint capsule and helps enable articulation of the joint. ${ }^{8}$ The synovial fluid in osteoarthritic joints contains a decreased concentration and molecular weight of hyaluronic acid compared with those found in healthy joints. ${ }^{8}$ The synovial fluid in osteoarthritic joints does not have the same elastic and viscous qualities as those of a healthy joint.

\section{Osteoarthritis of the Knee}

According to data from the Third National Health and Nutrition 
Examination Survey (NHANES, 1991-1993), 37.4\% of U.S. adults aged 60 years and older have radiographic OA of the knee, and $12.1 \%$-more than 4.3 million people-have symptomatic OA of the knee. ${ }^{9}$

\section{Demographics and Prevalence}

The demographics of OA of the knee are shown in Table 1.,10 Data published in 2006 from the Third NHANES showed that patients who had greater body mass index (BMI $\geq 30 \mathrm{~kg} / \mathrm{m}^{2}$ ), were older, were of non-Latino black heritage, and were male with manual labor occupations had higher odds of having both radiographic and symptomatic OA of the knee. ${ }^{9}$ Only symptomatic $\mathrm{OA}$ of the knee was significantly associated with self-reported activity limitations: difficulty walking, stooping, standing from a seated position, and stair climbing. Adults with symptomatic OA of the knee used significantly more assistive walking devices, had slower measured gait velocities, and used significantly more prescription nonsteroidal anti-inflammatory drugs (NSAIDs), narcotics, and over-the-counter acetaminophen. ${ }^{9}$ Prevalence data for OA of the knee among U.S. adults are presented in Table $2 .{ }^{9}$

\section{Pathophysiology}

Of all the large weight-bearing joints, the knee is where OA occurs most frequently. ${ }^{11}$ Although $\mathrm{OA}$ of the knee was once thought of as naturally occurring from the wear and tear of aging, more recent research shows important differences between aging knees and knees with OA: ${ }^{11}$

1. Degenerative changes are seen in non-weight-bearing surfaces and in weight-bearing joints.

2. Water content in cartilage of the aging joint does not change significantly, whereas the water content of cartilage in joints affected by $\mathrm{OA}$ increases early in the process.

3. Subchondral bone changes associated with OA are not seen in the aging joint.

\section{Risk Factors}

The primary risk factors for $\mathrm{OA}$ of the knee can differ across patient populations but generally include the following:

1. Genetic predisposition-Gene mutations may be a factor in predisposing individuals to development of $\mathrm{OA}$, although such information warrants further confirmation. ${ }^{12}$

2. Obesity-Recent analysis showed that obesity is linked to $\mathrm{OA}$ of the knee in women aged 50 years and older. ${ }^{13}$ Jinks et al. found that obese women (BMI $>30 \mathrm{~kg} / \mathrm{m}^{2}$ ) and overweight women (BMI $25-30 \mathrm{~kg} / \mathrm{m}^{2}$ ) with no knee pain at baseline had a 2.8-fold and 1.3-fold increased risk, respectively, for onset of severe knee pain at 3 years than did those with normal BMI $\left(<25 \mathrm{~kg} / \mathrm{m}^{2}\right)$. This study also suggested that $19 \%$ of cases of new-onset severe knee pain could be avoided by a 1-category downward shift in BMI (e.g., from obese to overweight or from overweight to

\section{TABLE 2 Prevalence of Osteoarthritis (OA) of the Knee in the United States Among Adults?}

\begin{tabular}{l|l}
\hline \multicolumn{2}{l}{ Radiographic OA of the Knee } \\
\hline All adults & $37.4 \%$ \\
Symptomatic_all adults* & $12.1 \%$ \\
Women & $42.1 \%$ \\
Men & $31.2 \%$ \\
\hline Severe $†$ OA of the Knee & $12.9 \%$ \\
\hline Women & $6.5 \%$ \\
Men & $1.6 \%$ \\
Adults who have undergone total knee replacement & \\
\hline * Prevalence of symptomatic radiographic OA of the knee did not differ by sex. \\
$\dagger$ Kellgren-Lawrence grade 3-4 changes. \\
OA = osteoarthritis.
\end{tabular}

normal). However, although unburdening weight-bearing joints could reduce the incidence of $\mathrm{OA}$ of the knee in overweight and obese people, Zhang et al., in a study of Chinese patients, demonstrated that OA could also progress in patients with low body weight. ${ }^{14}$ Compared with American women in the Framingham Osteoarthritis Study, ${ }^{15}$ Chinese women, a population with overall low BMI, had a higher prevalence of radiographic OA of the knee (43\% vs. 34\%) and a higher prevalence of symptomatic disease (15\% vs. $11 \%)$. The prevalence of $\mathrm{OA}$ of the knee in American and Chinese men was comparable. Speculative reasons for the higher prevalence of $\mathrm{OA}$ in Chinese women than in American women despite lower BMI include greater physical activity among the Chinese women and genetic factors.

3. Aging-Cartilage repairs itself at a slower rate over time. ${ }^{11} \mathrm{OA}$ of the knee affects older people; peak incidence occurs in women older than 75 years. ${ }^{11}$

4. Estrogen therapy-Postmenopausal women tend to have more $\mathrm{OA}$ of the knee than do men of similar age. ${ }^{16}$ The relationship between estrogen and $\mathrm{OA}$ in women is not clear. Although estrogen may provide joint protection, ${ }^{17}$ studies have reported a higher incidence of OA in the hips and knees of women undergoing short-term (fewer than 5 years) hormone therapy, a situation possibly due to more frequent medical care and diagnosis. ${ }^{18}$ Estrogen may be involved indirectly in the pathogenesis of $\mathrm{OA}$ by maintaining bone stiffness and directly by influencing collagen synthesis, including its suppression. Estrogen may also be linked to OA when a substantial inflammatory component or an immune response is present, rather than when a simple mechanical abnormality exists. ${ }^{19}$

OA of the knee is not always age dependent. The incidence of this disease is also related to occupation and sports involvement in relatively young adults. For example, employment in building 


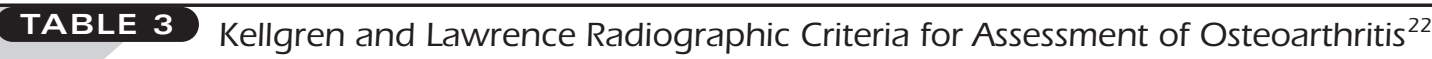

\begin{tabular}{|c|c|c|c|c|c|}
\hline Radiographic grade & 0 & 1 & 2 & 3 & 4 \\
\hline Classification & Normal & Doubtful & Mild & Moderate & Severe \\
\hline Description & $\begin{array}{l}\text { No features of } \\
\text { osteoarthritis }\end{array}$ & $\begin{array}{l}\text { Minute osteophyte; } \\
\text { doubtful significance }\end{array}$ & $\begin{array}{l}\text { Definite osteophyte; } \\
\text { normal joint space }\end{array}$ & $\begin{array}{l}\text { Moderate joint-space } \\
\text { reduction }\end{array}$ & $\begin{array}{l}\text { Joint space greatly } \\
\text { reduced; subchondral } \\
\text { sclerosis }\end{array}$ \\
\hline
\end{tabular}

\section{TABLE 4 American College of Rheumatology Criteria for Classification of Idiopathic Osteoarthritis $(O A)$ of the Knee ${ }^{24}$}

\begin{tabular}{|c|c|c|}
\hline Clinical and Laboratory & Clinical and Radiographic & Clinical \\
\hline $\begin{array}{l}\text { Knee pain }+\geq 5 \text { of } 9 \text { : } \\
\text { - Age older than } 50 \text { years } \\
\text { - Stiffness }<30 \text { minutes } \\
\text { - Crepitus } \\
\text { - Bony tenderness } \\
\text { - Bony enlargement } \\
\text { - No palpable warmth } \\
\text { - ESR }<40 \mathrm{~mm} / \mathrm{h} \\
\text { - Rheumatoid factor }<1: 40 \\
\text { - SF OA }\end{array}$ & $\begin{array}{l}\text { Knee pain }+\geq 1 \text { of } 3 \text { : } \\
\text { - Age older than } 50 \text { years } \\
\text { - Stiffness }<30 \text { minutes } \\
\text { - Crepitus } \\
\text { - + Osteophytes }\end{array}$ & $\begin{array}{l}\text { Knee pain }+\geq 3 \text { of } 6 \text { : } \\
\text { - Age older than } 50 \text { years } \\
\text { - Stiffness }<30 \text { minutes } \\
\text { - Crepitus } \\
\text { - Bony tenderness } \\
\text { - Bony enlargement } \\
\text { - No palpable warmth }\end{array}$ \\
\hline $92 \%$ sensitive & 91\% sensitive & $95 \%$ sensitive \\
\hline $75 \%$ specific & $86 \%$ specific & $69 \%$ specific \\
\hline
\end{tabular}

$E S R=$ erythrocyte sedimentation rate (Westergren); SF OA= synovial fluid signs of osteoarthritis (clear, viscous, or white blood cell count $<2,000 / m m{ }^{3}$ ).

and construction trades for as few as 11 years is associated with an almost 4-fold increased risk of OA of the knee. ${ }^{19}$ Interestingly, while men who work in farming do not have a higher risk for $\mathrm{OA}$ of the knee, women who have worked in agriculture for more than a single decade have more than a 2 -fold increased risk of knee arthritis. ${ }^{20}$ Increased risk of OA of the knee has also been found among athletes active in various sports, including soccer (1.6-fold increased risk), ice hockey (1.9-fold increased risk), and tennis (2-fold increased risk). ${ }^{21}$

Additional risk factors include trauma; repetitive stress injuries (walking, lifting weights); rheumatoid arthritis; other forms of inflammatory arthritis, such as repeated episodes of gout or septic arthritis; and metabolic abnormalities (hypothyroidism, hyperparathyroidism, bone dysplasias) ${ }^{11}$ Evidence shows that regular, moderate use of healthy joints does not increase the risk for OA and can help maintain overall health, muscle strength, and range of motion. ${ }^{11}$

\section{Diagnosis}

The major symptoms of $\mathrm{OA}$ of the knee are use-related pain, stiffness, and loss of movement. Major signs include bony swelling, crepitus (a grinding noise or sensation within a joint), joint-margin tenderness, cool effusion, decreased range of movement, and instability. ${ }^{22}$ Typically, patients initially come to clinicians because of pain. At first presentation, no radiologic evidence of the disease may be present, making diagnosis 
difficult. 22

The Kellgren and Lawrence system for the classification of OA assigns a severity grade (0-4) at various joint sites-knee, hip, hand, and spine-according to joint site and x-ray findings (Table 3). ${ }^{22}$ However, the prominence of changes in radiographic osteophytes at all joint sites is controversial, and no single global system is suitable for the assessment of $\mathrm{OA}$ at all sites. The criteria for increasing severity relate to the assumed sequential appearance of osteophytes, joint-space loss, subchondral sclerosis, and formation of cysts. Grading is performed by comparing the index radiograph against reproductions in a radiographic atlas, although it is important to note that radiographic grade does not reliably correlate with symptoms. ${ }^{23}$ As the disease progresses, joint space decreases, and formation of osteophytes and thickening of the synovial membrane occur. At the end stage of the disease, full-thickness loss of articular cartilage is seen, as well as thickening of the subchondral bone, cysts, obvious osteophytes, and stiffness/immobility of the joint. ${ }^{22}$

According to the American College of Rheumatology (ACR), a diagnosis of $\mathrm{OA}$ of the knee can be established by using any of 3 methods (Table 4). ${ }^{24}$ The selected method depends on the types of data available to the clinician. As shown in Table 4, the ACR analysis demonstrates that a combination of clinical and radiographic criteria yields the best combination of sensitivity and specificity and is the most common method of diagnosis in clinical practice. The number of radiographic changes of $\mathrm{OA}$ of the knee can be visualized, particularly in the elderly. Unfortunately, a poor correlation exists between radiographic findings and severity of clinical symptoms ${ }^{23}$; therefore, attributing knee pain to OA based on radiographic evidence alone can lead to diagnostic and therapeutic errors.

\section{Treatment}

Because no curative treatment exists, the goals for treating OA of the knee are to relieve pain, slow disease progression, improve joint biomechanics, improve muscle strength and conditioning, delay total knee replacement (TKR), and preserve functional independence, mobility, and quality of life. ${ }^{25}$ Treatment of OA of the knee should be individualized. Before initiating treatment, practitioners must exclude other causes of musculoskeletal pain, including referred pain, bursitis, and inflammatory rheumatic diseases.

\section{Nonpharmacologic Therapy}

Exercise, weight loss, and education are the cornerstones of nonpharmacologic treatment. ${ }^{26}$ Only a small number of randomized, controlled clinical trials have evaluated nonpharmacologic interventions in $\mathrm{OA}$. However, practical management strategies have evolved from clinical observations and controlled trials. These strategies include patient education and support, unloading and protection of involved joints,

\section{TABLE 5 Pharmacologic Therapy for Patients With Osteoarthritis*26}

\section{- Oral}

- Acetaminophen

- Cyclooxygenase-2-specific inhibitor (celecoxib)

- Nonselective nonsteroidal anti-inflammatory drug (misoprostol or a proton pump inhibitor should be added in patients at high risk of upper gastrointestinal adverse events)

- Nonacetylated salicylate (choline magnesium trisalicylate, salsalate)

- Weak mu $(\mu)$ opioid agonist (tramadol)

- Strong mu $(\mu)$ opioid agonist (e.g., codeine)

- Chondroitin/glucosamine

- Intra-articular

- Glucocorticoids

- Hyaluronan

- Topical

- Capsaicin

- Methylsalicylate

* The choice of agent should be individualized on a per-patient basis.

strengthening of the muscles around joints, and local pain relief measures, including application of heat and cold.

Patient education is an integral part of the treatment plan. Patients should be encouraged to participate in self-management programs. Social support via routine telephone contact may also be a cost-effective intervention. ${ }^{26}$

The ACR has recommended a number of nonpharmacologic therapies that can help the patient meet some or all of his or her treatment goals. ${ }^{26}$ For overweight patients, a weight loss program should be instituted. A cane or splint may also be used to reduce the load on weight-bearing joints. Joints may be protected by avoiding activities that cause unwarranted stress (such as kneeling and squatting). A variety of exercises, including aerobics and motion and strength training, may be used to strengthen the appropriate muscles, either under the supervision of a physical therapist or at home. Other treatment methods can be used, including using patellar taping, wearing medial- or lateral-wedged insoles, and/or using an unloader brace designed to decrease the load supported by a single side of the knee joint.

\section{Pharmacologic Therapy}

Pain relief is the primary indication for systemic drug therapy in patients with OA of the knee. Drug therapy for pain management is most effective when coupled with nonpharmacologic strategies. ${ }^{26}$ No pharmacologic agents are available that reverse the structural or biochemical abnormalities of the disease. Table 5 presents many of the medications used to treat $\mathrm{OA}$ of the knee. ${ }^{26}$ The standards of therapy are acetaminophen and NSAIDs, and opioids, topical analgesics, and intra-articular glucocorticoids. ${ }^{26,27}$

Guidelines recommend acetaminophen as the initial drug of 
choice, followed by NSAIDs and then opioid analgesics. ${ }^{26}$ Opioid analgesics, such as propoxyphene, codeine, or oxycodone, are not well suited for long-term use, due to the development of tolerance, dependence, and side effects. ${ }^{26}$ However, shortterm use of these agents may be helpful in treating acute pain. In patients with $\mathrm{OA}$ of the knee who have mild to moderate pain, who do not respond to acetaminophen, and who opt not to undergo systemic therapy, the use of topical analgesics is recommended as either adjunctive treatment or as monotherapy. ${ }^{26}$ In a few short-term trials, significant reduction of pain measures was observed with topical $0.025 \%$ capsaicin $^{28}$; with topical 5\% lidocaine patch, significant reduction of pain and improvement of stiffness and physical function was observed. ${ }^{29,30}$

\section{Acetaminophen}

Acetaminophen, at doses up to $4 \mathrm{~g}$ per day, is the recommended initial drug of choice for systemic treatment of symptomatic $\mathrm{OA}$ of the knee. ${ }^{26}$ In some randomized, placebo-controlled trials, acetaminophen 2-4 g per day significantly reduced pain associated with $\mathrm{OA}$; in meta-analyses, acetaminophen was found to relieve pain due to OA by $79 \%$ to $87 \% .^{31,32}$ At therapeutic doses, acetaminophen provides symptom relief equivalent to that obtained with NSAIDs but with fewer gastric adverse effects. However, 2 studies of patients with OA demonstrated a greater preference for NSAIDs than for acetaminophen, although many patients continued to take acetaminophen. ${ }^{33,34}$ Although acetaminophen is the most commonly used analgesic in the United States, it should be used with caution because of the risk of hepatotoxicity.

Acute acetaminophen ingestion and toxicity are rare; the observed incidence in one local study was 21.4 and 4.8 cases per 100,000/year, respectively. ${ }^{35}$ However, acetaminophen is the most common cause of acute liver failure ${ }^{36} \mathrm{~A}$ recent study showed that $42 \%(275 / 662)$ of cases of acute liver failure were caused by the use of acetaminophen, and unintentional acetaminophen overdose accounted for almost 50\% of these cases. ${ }^{36}$ Most patients with acetaminophen-induced acute liver failure (79\%) reported taking the products specifically for pain. Clinical pictures and outcomes were similar for the intentional and unintentional overdoses, with a mortality rate of $29 \%$ and liver transplantation in $7 \%$ and $9 \%$ of cases, respectively. Patients with liver failure from unintentional overdose were more likely to be taking several products containing acetaminophen (38\%) and were more likely to be using prescription products containing a combination of acetaminophen and narcotics (63\%). The most popular of these combinations was acetaminophen with hydrocodone. The investigators found that individuals were taking more than the maximum dose of $4 \mathrm{~g}$ per day recommended on product package inserts; the mean daily dose in this group was $7.5 \mathrm{~g}(1.0-7.8 \mathrm{~g}){ }^{36}$

When taken as directed, acetaminophen is safe, although there is evidence that regular, daily intake of $4 \mathrm{~g}$ of acetaminophen in healthy adults is associated with a higher rate of elevated alanine aminotransferase level, compared with placebo: up to $44 \%$ vs. $0 \%$ incidence of levels 3 times the normal limit. ${ }^{37}$ It should be stressed that, if a patient has elevated liver enzymes, recent acetaminophen use should be investigated as a possible cause. In addition, acetaminophen can prolong the half-life of warfarin sodium; therefore, careful monitoring of the prothrombin time is recommended in patients taking warfarin who subsequently begin high-dose acetaminophen treatment. ${ }^{38}$

Recent evidence shows that, with physician supervision, $4 \mathrm{~g}$ per day of acetaminophen is generally well tolerated and does not result in extremely high hepatic enzyme levels in patients with OA of the knee when taken for up to 12 months. ${ }^{39}$ Regardless, education of patients, physicians, and pharmacists should be aimed at monitoring, if not limiting, the use of this drug in high-risk patients, and patients should be cautioned about the increased risk of liver damage, especially if they chronically consume alcohol.

\section{NSAIDs and Cyclooxygenase-2 Inhibitors}

If pain is not resolved with use of acetaminophen, NSAIDs are the agents of choice. ${ }^{26}$ NSAIDs have demonstrated efficacy in treating pain associated with OA of the knee. In a meta-analysis of 23 randomized placebo-controlled trials, 2 to 13 weeks of treatment with NSAIDs, compared with placebo, was found to be $15.6 \%$ more effective in treating pain, as assessed using a visual analog scale (VAS). ${ }^{40}$ The choice to prescribe an NSAID should be made after evaluating risk factors for serious upper GI conditions and renal toxicity. Specifically, in older adults, NSAIDs have become a leading cause of GI-related hospitalization and may increase the risk of death from ulceration more than 4-fold. ${ }^{41}$ Risk factors for upper GI bleeding in patients treated with NSAIDs include age of 65 years and older, history of peptic ulcer disease or upper GI bleeding, concomitant use of oral glucocorticoids or anticoagulants, comorbidity, and, possibly, smoking or alcohol consumption. ${ }^{26}$

NSAIDs are associated with an increased risk of serious GI adverse events, including bleeding, ulceration, and perforation of the stomach or intestines, which can be fatal. ${ }^{26}$ These events can occur at any time during use and without warning symptoms. Elderly patients are at greater risk of serious GI events. Patients who are at higher risk of GI adverse reactions should be prescribed misoprostol or a proton pump inhibitor in conjunction with the NSAID. ${ }^{25}$

Cyclooxygenase-2 (COX-2) inhibitors have been demonstrated to be effective in the treatment of patients with $\mathrm{OA}$; for example, in a randomized trial in patients with $\mathrm{OA}$ of the knee, treatment with $12.5 \mathrm{mg}$ or $25 \mathrm{mg}$ per day of rofecoxib or $200 \mathrm{mg}$ per day of celecoxib resulted in significant relief of pain on walking, pain at rest, night pain, and morning stiffness. At 6 weeks of treatment, up to $60 \%$ reported good or excellent response in global assessment, compared with 39\% taking $4 \mathrm{~g}$ 
per day of acetaminophen. ${ }^{42}$ Furthermore, endoscopic evidence shows that COX-2 inhibitors produce a lower incidence of gastroduodenal ulcers than do traditional NSAID treatment. ${ }^{43}$

However, COX-2 inhibitors have been associated with a low but significantly increased cardiovascular risk, warranting consideration of baseline cardiovascular risk. Long-term use in patients at risk for recurrent colon polyps is associated with a 2- to 3-fold increased risk of serious adverse cardiovascular events, and a 2-fold increased cardiovascular risk is observed when COX-2 inhibitors are used immediately after coronary artery bypass surgery. ${ }^{44} \mathrm{~A}$ thorough review of COX-2 inhibitor data by the FDA resulted in the following conclusions ${ }^{44}$ :

1. COX-2 inhibitors, as a class, are associated with an increased risk of serious cardiovascular adverse events, including stroke and myocardial infarction.

2. Available data do not permit a rank ordering of COX-2 medications according to cardiovascular risk.

3. Pending the availability of additional long-term controlled clinical trial data, the available data are best interpreted as consistent with a class effect of increased risk with the use of COX-2 selective and nonselective NSAIDs.

4. Short-term use to relieve acute pain, particularly at low doses, does not appear to confer increased risk.

\section{Tramadol}

Tramadol, a centrally acting oral analgesic, is a weak $m u(\mu)$ opioid agonist that also inhibits reuptake of norepinephrine and serotonin. ${ }^{26}$ The agent has been approved by the FDA for the treatment of moderate to severe pain and might be used in patients who have contraindications, including impaired renal function, to COX-2-specific inhibitors and nonselective NSAIDs, or in patients who have not responded to previous oral therapy. Although numerous study results assessing the use of tramadol in general pain have been published, few controlled studies have evaluated its use in OA. However, the efficacy of tramadol is comparable with that of ibuprofen in patients with OA of the hip and of the knee. ${ }^{45}$

\section{Glucosamine and Chondroitin}

Glucosamine and chondroitin sulfate are used to treat OA. Both are naturally occurring substances found in and around the cells of cartilage..$^{46}$ Glucosamine is an amino sugar that the body produces and distributes in cartilage and other connective tissue; chondroitin sulfate is a complex carbohydrate that helps cartilage retain water. In the United States, glucosamine and chondroitin sulfate are sold as dietary supplements, which are regulated as foods rather than drugs.

The multicenter, double-blind, placebo- and celecoxibcontrolled Glucosamine/chondroitin Arthritis Intervention Trial evaluated their efficacy and safety as a treatment for OA of the knee. ${ }^{46}$ The mean age of patients was 59 years, and 64\% were women. More than 1,500 people enrolled in the study. All were aged 40 years or older and had OA of the knee, mild or moderate to severe knee pain, and a loss of cartilage in the affected knee. Patients were randomly assigned to receive glucosamine alone, chondroitin sulfate alone, glucosamine and chondroitin sulfate combined, celecoxib, or a placebo for 24 weeks.

Overall, glucosamine and chondroitin sulfate were not significantly better than placebo in reducing knee pain by 20\% (the primary outcome measure). For participants with mild pain, relief was not significantly better with glucosamine $(P=0.30)$, chondroitin $(P=0.17)$, or both $(P=0.09)$ than with placebo. For a small group of participants with moderate to severe pain, glucosamine combined with chondroitin provided significant pain relief compared with placebo $(P=0.002)$. However, because of the small size of the group, the researchers noted that this finding is preliminary and must be confirmed in additional studies. Participants taking celecoxib, compared with placebo $(P=0.008)$, experienced significant pain relief, as expected. The researchers concluded that recent positive study results do not change the cornerstones of OA managementeducation, exercise, physical therapy, weight reduction, and simple analgesics_even though glucosamine and chondroitin may be another effective therapeutic option for managing pain in selected patients with $\mathrm{OA}^{46}$

\section{Glucocorticoid Injections}

Intra-articular injections of glucocorticoids can relieve acute knee pain, particularly in patients who have signs of local inflammation with joint effusion. ${ }^{26}$ A large meta-analysis of 28 randomized controlled trials in patients with $\mathrm{OA}$ of the knee demonstrates that treatment with intra-articular glucocorticoids has short-term efficacy, persisting for about 4 weeks for pain reduction and about 1 week for global endpoints. ${ }^{47}$

In comparisons of corticosteroids and HA products, no statistically significant differences were, in general, detected at 1 to 4 weeks postinjection. Between 5 and 13 weeks postinjection, HA products were more effective than corticosteroids for 1 or more of the following variables: WOMAC OA Index, Lequesne Index, pain, range of motion (flexion), and number of responders. ${ }^{47}$

In the painful and swollen joint, the procedure is to aspirate fluid and then intra-articularly inject a glucocorticoid preparation, such as triamcinolone hexacetonide $10-40 \mathrm{mg}$ or prednisone acetate $10-25 \mathrm{mg} .^{48}$ Glucocorticoid injection can be used as monotherapy or as an adjunct to systemic therapy with an analgesic, an NSAID, or a COX-2 inhibitor. ${ }^{25}$ Joints should be aspirated/injected using aseptic technique, and the fluid should be evaluated for a cell count. Some patients may experience a mild flare of synovitis due to a reaction to the crystalline steroid suspensions; however, these flares are transient and can be relieved with analgesics and cold compresses. If standard aseptic technique is used, the risk of introducing infection into a joint with $\mathrm{OA}$ is extremely low. A gram stain and culture should be performed if infection is suspected. 


\begin{tabular}{|c|c|}
\hline Intra-articular Hyaluronans & Characteristics \\
\hline Hyaluronic acid & $\begin{array}{l}\text { - Naturally occurring } \\
\text { - Also known as sodium hyaluronate } \\
\text { - Long, nonsulfated, straight chains of } \\
\text { variable length } \\
\text { - Repeating disaccharide unit of } \\
\text { N-acetylglucosamine and glucuronic } \\
\text { acid } \\
\text { - Forms a randomized coil in } \\
\text { physiological solvents } \\
\text { - Average molecular weight 4-5 million d }\end{array}$ \\
\hline Hylans & $\begin{array}{l}\text { - Synthetic } \\
\text { - Cross-linked hyaluronan chains in } \\
\text { which the carboxylic and N-acetyl } \\
\text { groups are unaffected } \\
\text { - Average molecular weight } 6 \text { million d } \\
\text { - Can be water-soluble as a gel } \\
\text { (e.g., hylan B) or membrane bound }\end{array}$ \\
\hline
\end{tabular}

Contraindications to intra-articular glucocorticoid injection include infection in or around the joint, bacteremia or sepsis, significant skin breakdown at the injection site, osteochondral or other intra-articular fracture at the joint to be injected, and severe joint destruction (e.g., Charcot's joint). ${ }^{48}$ Other, uncommon potential side effects of intra-articular glucocorticoid treatment include tendon weakening and rupture, fat atrophy, and muscle wasting precipitated by misdirected injections; nerve and blood vessel damage, due to misdirected injections; steroid arthropathy; and systemic effects caused by high doses and multiple simultaneous injections. ${ }^{48}$

\section{Total Knee Replacement}

TKR is a last resort for treating OA-associated knee pain and is not always preferred by patients. Yet the procedure is becoming more commonplace. The prevalence of primary knee arthroplasty (TKR) has tripled in the United States, from 129,000 in 1990 to 381,000 in $2002 .{ }^{49}$ By 2030, the number of primary TKRs is expected to jump by more than 9 times to 3.5 million.

In a Wisconsin study of TKR costs from 1990 to 2000, total charges for TKR ballooned from $\$ 69$ million to $\$ 148$ million-a $107 \%$ inflation-adjusted increase. ${ }^{50}$ Kurtz estimated that a $1 \%$ reduction in TKR revision surgeries alone could save between $\$ 53.5$ million and $\$ 98.4$ million per year in the United States. ${ }^{49}$

As the number of primary procedures increases, and these procedures are performed on younger patients, it is expected that revision surgeries will increase as well. An examination of U.S. TKR data from 1990 to 2002 found a TKR revision rate of $8.2 \% .{ }^{49}$ Between 1990 and 2002, the rate of TKR revision increased by 146\%-from approximately 12,000 revision surgeries in 1990 to 35,000 in 2002. Currently, the average total charge for TKR revision surgery is more than $\$ 73,000$, with substantially higher costs for patients undergoing surgery because of deep joint infection or for those receiving more complex implants. ${ }^{49}$ The number of revision procedures is expected to increase $62 \%$ to almost 57,000 in 2030. Projected costs to the hospital alone for these procedures may exceed $\$ 2$ billion by 2030 . Reimbursement rates will not cover hospital costs for this procedure, despite recent increases in Medicare payments for revision arthroplasty. ${ }^{49}$

\section{Viscosupplementation Using Hyaluronic Acid}

Another approach in the palliation of joint pain is viscosupplementation using intra-articular hyaluronan preparations (Table 6). ${ }^{8}$ Hyaluronan and hylan products (HAs) provide an opportunity to treat $\mathrm{OA}$ pain in knee joints.

\section{Rationale for Using Viscosupplementation}

Viscosupplementation with HA products helps to improve the physiologic environment in an osteoarthritic joint by supplementing the shock absorption and lubrication properties of osteoarthritic synovial fluid. ${ }^{51,52}$ The rationale for using viscosupplementation is to restore the protective viscoelasticity of synovial hyaluronan, decrease pain, and improve mobility. The immediate benefits of viscosupplementation are the relief of pain. Longer-term benefits are believed to include the return of joint mobility by the restoration of transsynovial flow and, ultimately, the metabolic and rheologic homeostasis of the joint. ${ }^{51}$

\section{Types of HA Available in the United States}

Two types of HAs are available in the United States-naturally occurring hyaluronan (low molecular weight [0.5-3.6 million d] and hylan G-F 20 (high molecular weight [6 million d]), 53,54 which are derived from rooster combs or bacterial cultures, purified, and then isolated in noninflammatory form. ${ }^{55}$ Although the indications for these products are the same-the treatment of pain associated with OA of the knee in patients who have failed to respond adequately to conservative nonpharmacologic therapy and to simple analgesics such as acetaminophen-they differ with respect to physical properties, number of injections per treatment course, and duration of effect. ${ }^{54-58}$ Direct comparisons of duration of effect have not been performed.

Table 7 lists the products approved for use in patients with OA of the knee, as well as these physical properties. ${ }^{54-58}$ The ACR added viscosupplementation to its OA treatment algorithm in 2000, making this therapy a viable option along with NSAIDs, COX-2 inhibitors, and glucocorticoid injections (Figure 1). ${ }^{26}$

Hylans are cross-linked HAs, which give them a higher molecular weight and increased elastoviscous properties. ${ }^{53,59}$ The higher molecular weight of hylan may make it more efficacious than naturally occurring HA because of its enhanced elastoviscous properties and its longer period of residence in the 
TABLE 7 Comparison of Hyaluronate Products ${ }^{54-58}$

\begin{tabular}{|c|c|c|c|c|c|}
\hline Product & $\begin{array}{c}\text { Euflexxa } \\
\text { (1\% Sodium } \\
\text { Hyaluronate) }\end{array}$ & $\begin{array}{l}\text { Hyalgan (Sodium } \\
\text { Hyaluronate) }\end{array}$ & $\begin{array}{c}\text { Orthovisc } \\
\text { (High- Molecular-Weight } \\
\text { Hyaluronan) }\end{array}$ & $\begin{array}{l}\text { Supartz (Sodium } \\
\text { Hyaluronate) }\end{array}$ & $\begin{array}{c}\text { Synvisc } \\
\text { (Hylan G-F 20) }\end{array}$ \\
\hline Dose per injection (mg) & 20 & 20 & 30 & 25 & 16 \\
\hline $\begin{array}{l}\text { Number of injections per } \\
\text { treatment course }\end{array}$ & 3 & $3-5$ & 3 or 4 & 5 & 3 \\
\hline Duration of pain relief & 3 months & $\begin{array}{l}3 \text { injections: } \\
2 \text { months } \\
5 \text { injections: } \\
6 \text { months }\end{array}$ & 6 months & 6 months & 6 months \\
\hline $\begin{array}{l}\text { Molecular weight* } \\
\left(\times 10^{6} \mathrm{~d}\right)\end{array}$ & $2.4-3.6$ & $0.5-0.7$ & $1.0-2.9$ & $0.6-1.2$ & 6.0 \\
\hline
\end{tabular}

\section{FIGURE 1 Treatment Summary for Osteoarthritis of the Knee}

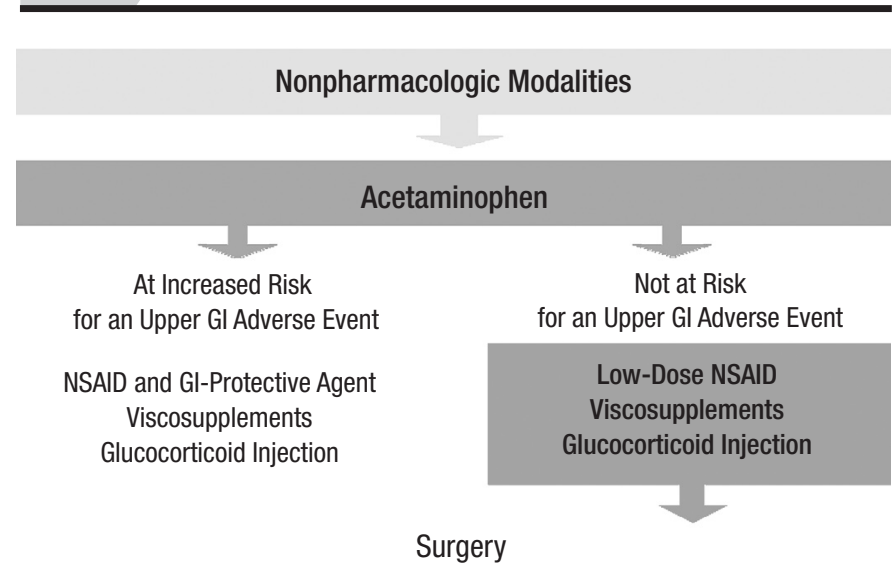

Adapted with permission from the American College of Rheumatology. ${ }^{26}$ $G I=$ gastrointestinal; NSAID = nonsteroidal anti-inflammatory drug.

joint space because of slower resorption. ${ }^{52}$ Studies have shown that the higher-molecular-weight, more elastoviscous hylan G-F 20 has a large treatment effect compared with placebo. ${ }^{60}$ The actual period that the injected HA product stays within the joint space is hours (naturally occurring HA) to weeks (hylan B), but the time of clinical efficacy is usually months, ${ }^{55-59}$ suggesting additional mechanisms of action.

For example, relief of knee pain in OA using HA supplementation may be at least partially due to direct effects on nerve impulses and nerve sensitivity. Knee joint inflammation excites the nociceptors of articular nerves, making them exquisitely sensitive. ${ }^{61}$ Administration of HA significantly decreases ongoing and movement-evoked nerve activity. ${ }^{61,62} \mathrm{HA}$ also has a range of effects at the cellular level:

1. It can enhance the synthesis of proteoglycans and of extracellular matrix proteins, including chondroitin. ${ }^{8}$

2. It can alter the profile of inflammatory mediators and expression/activity of matrix-degrading enzymes in such a way that the balance is tipped away from cell matrix degradation to cell matrix synthesis.

3. It acts as an antioxidant by enhancing the scavenging effect of synovial fluid, reducing reactive oxygen species and thereby protecting articular tissues from oxidative damage. ${ }^{63}$

4. It affects immune cells. HA supplementation can modulate leukocyte function, including macrophage phagocytosis, a process that is more pronounced in higher-molecularweight HA. ${ }^{64}$ It can also inhibit neutrophil-induced cartilage destruction, again, in a dose- and molecular-weightdependent manner, with higher-molecular-weight hylans providing greater protection. ${ }^{65}$

\section{Advantages and Disadvantages of HA}

Results from several clinical studies, preclinical experiments, and meta-analyses indicate that viscosupplementation with different HA products has several advantages, particularly for some subpopulations of patients. A meta-analysis of 20 randomized controlled trials showed that overall, HA viscosupplementation therapy significantly decreases symptoms of $\mathrm{OA}$ of the knee. ${ }^{60}$ In clinical trials of HA preparations, pain relief among patients was comparable with that of oral NSAIDs. ${ }^{51,60,66}$ One randomized controlled trial showed that for resting pain relief, HA is as effective as NSAIDs and is superior to NSAIDs alone in relieving pain associated with physical activity and functional performance. ${ }^{67}$ Compared with intra-articular glucocorticoid injections, pain relief is achieved more slowly with HA injections, 
but their effect may last considerably longer. ${ }^{51,68,69}$

In the meta-analysis, HA viscosupplementation was less likely to be beneficial for patients aged 65 years and older as well as those with the most advanced radiographic stage of OA. ${ }^{60}$ A study of 4,253 patients with OA of the knee found that with short-term treatment with intra-articular hylan G-F 20, potential predictors of efficacy in pain reduction included being underweight, being male, having severe baseline pain, and having a recent diagnosis ( $<1$ year and $1-5$ years vs. 10 years). ${ }^{70}$ Two other studies also demonstrate lesser efficacy with more severe symptoms: patients with more advanced radiographic grades were less likely to respond to HA therapy. ${ }^{67,71}$

Intra-articular hyaluronans are well tolerated in clinical trials and practice. ${ }^{51}$ The most common adverse event associated with intra-articular hyaluronans is mild, short-lasting injection site pain and inflammation. Major adverse events associated with intra-articular hyaluronans are rare: in the trials included in the meta-analysis, the overall incidence of serious events, including severe swelling, vasculitis, hypersensitivity reaction, and painful acute local reaction, was $0.36 \%(4 / 1,141){ }^{60}$ The pooled relative risk of transient mild increase in local pain or swelling was 1.19 (95\% confidence interval [CI], 1.01 to 1.41 ). In addition to these potential adverse effects, another drawback for some patients is the need for a series of 3 to 5 weekly HA injections. ${ }^{72}$ It is therefore recommended that this approach be reserved for patients with symptoms and a significant need for surgery and for patients with mild $\mathrm{OA}$ in whom more conservative approaches-physical therapy, weight loss, NSAID, and intraarticular glucocorticoids—have failed. ${ }^{66}$

\section{Studies Involving Viscosupplementation Meta-analyses}

Recent meta-analyses have concluded that viscosupplementation using HA and HA products is (1) efficacious and safe and (2) lasts longer than intra-articular glucocorticoids. In 2004, a meta-analysis was conducted by Wang et al. to evaluate the therapeutic efficacy and safety of the procedure. Twenty blinded, randomized, placebo-controlled trial results published between 1966 and 2001 met the inclusion criteria. ${ }^{60}$ The outcome measure of safety was relative risk for adverse events and the outcome measure for efficacy was scores of pain with activity, pain without activity, and function. This study includes data on 1,647 randomly assigned knees: 818 treated with HA and 829 with placebo. This meta-analysis confirmed that intra-articular injection of cross-linked and non-cross-linked HA, compared with placebo, decreases symptoms of $O A$ of the knee and revealed significant improvements in pain with activity, pain at rest, and function, with few adverse events reported. The relative risk of minor adverse events with HA was 1.19 (95\% CI, 1.01 to 1.41). Trials that involved cross-linked HA showed much greater pooled estimates of efficacy than did the trials involving non-crosslinked HA. However, among trials using non-cross-linked HA, there was significant between-study heterogeneity in estimates of efficacy and, therefore, relative efficacy is inconclusive.

Bellamy et al. conducted a systematic review using Cochrane methodology to evaluate the safety and efficacy of HA products. ${ }^{51}$ The Cochrane Review concluded that, overall, the analyses showed positive results for the HA class. Results were particularly positive for some products with respect to certain variables and time points, such as pain on weight bearing at 5 to 13 weeks postinjection. Forty trials included comparisons of HA preparations and placebo; 10 trials included comparisons of intra-articular glucocorticoids; 6 trials of NSAIDs; 3 trials of physical therapy; 2 trials of exercise; 2 trials of arthroscopy; 2 trials of conventional treatment; and 15 trials of other hyaluronans/hylan. The pooled analyses of the effects of viscosupplementation against placebo controls supported the efficacy of this type of intervention in OA of the knee. In these same analyses, varied efficacy was observed for different HA products on different variables and at different time points. Notably, the 5- to 13-week postinjection period showed an improvement from baseline of 28\% to 54\% for pain and 9\% to $32 \%$ for function. In general, efficacy was comparable with the NSAIDs, and longer-term benefits were seen in comparison with intra-articular glucocorticoids.

\section{Notable Individual Studies-Comparative Effectiveness}

The few head-to-head human clinical trials that have been published have not consistently demonstrated a clear advantage in efficacy for one product over another. However, some study results suggest that higher-molecular-weight $\mathrm{HA}$ is more efficacious. A recent prospective, randomized clinical trial compared hylan G-F 20 (3 injections) $(\mathrm{n}=181)$ with sodium hyaluronate (5 injections) $(n=167)$ in 392 patients with predominantly grade $3 \mathrm{OA}$ of the knee. Pain was measured on a 10-cm VAS of 0 (no pain) to 10 (worst pain). By 6 weeks, knee pain on the VAS improved from 6.7 to $3.2(P=0.02)$, with an intergroup difference of $P=0.001$, and was sustained until 12 months (VAS of $3.7[P=0.04]$ ) with hylan $G-F 20$, with an intergroup difference of $P=0.01$ (intergroup differences in favor of the hylan G-F 20 group). Western Ontario and McMaster Universities Osteoarthritis Index (WOMAC) pain and function scores were significantly superior for hylan G-F 20 at 3 months $(P=0.02), 6$ months $(P=0.01)$, and 12 months $(P=0.02) .{ }^{73}$ Several studies of HA products for OA of the knee have demonstrated no benefit compared with controls; possibly, at least in some cases, because of the age and OA severity of the patient population assessed..$^{51,74}$

In the hyaluronate group, pain improved from 6.6 to 5.7 at 6 weeks $(P>0.05)$ and to 4.1 at 3 months $(P=0.04)$ but was sustained only until 6 months (VAS, 5.9; $P>0.05$ ).

General patient satisfaction was better in the hylan group at all times, although it was only statistically significant at 3 months $(P=0.01)$ and 6 months $(P=0.02)$. Patient adherence 
was $99.2 \%$ in the hylan group versus $92.2 \%$ in the hyaluronate group with regard to the number of injections. This finding, however, may be confounded by differences in the number of injections required for the 2 treatment groups: 3 in the hylan group and 5 in the hyaluronate group.

The cost of the agents was comparable, but the total treatment cost was 23\% more in the hyaluronate group because of 2 additional visits to complete the 5-injection treatment course. Thus, although both treatments relieved pain significantly, treatment with hylan G-F 20 relieved pain earlier and the effect was sustained longer.

Pain relief with a low incidence of adverse events using viscosupplementation with hylan has been reported for up to 18 months. ${ }^{75}$ Repeat treatment may extend pain relief in patients who experienced beneficial results with an initial course of therapy. Although only limited information is available, an analysis of 255 patients with OA of the knee suggests that these agents are effective and safe when given repeatedly. ${ }^{76}$ Karatosun et al. performed a randomized controlled trial comparing 1 series of HA injections with progressive knee exercises in 105 patients. ${ }^{77}$ The investigators followed up with the patients for 18 months. No significant differences were observed between the study arms in terms of pain and function scores following treatment at 18 months. However, the HA injections also increased the levels of satisfaction of the patients with $\mathrm{OA}$, an important consideration in patients who may not be able or willing to adhere to a steady exercise regimen.

A prospective open-label study by Waddell et al. evaluated the efficacy and tolerability of a second course of hylan G-F 20 for the treatment of OA-associated knee pain over a 12-month period in patients who had previously experienced a beneficial initial course of therapy. ${ }^{50}$ The main efficacy measure was the WOMAC index question Al, which assessed the patient's pain while he or she walked on a flat surface. All efficacy parameters significantly improved $(P<0.001)$ from baseline at weeks $1,2,4$, $8,12,26$, and 52 . Improvements from baseline to weeks 26 and 52 for WOMAC index question Al were 1.4 and 1.1 (1-category shifts), respectively (Figure 2).

While the study design undermines conclusions-patients may have improved without viscosupplementation and results may be confounded by investigator and patient biases-the authors argue that the beneficial effects were likely due to viscosupplementation. Before the study, patients had achieved similar degrees of improvement with viscosupplementation and then worsening of symptoms after completing the course of treatment.

\section{Possible Delay of TKR With HA}

A few studies suggest that the use of HA products could delay the need for TKRs and generate savings in the managed care setting. In a retrospective analysis of patients with advanced $O A$ of the knee awaiting TKR, hylan G-F 20 effectively managed

\section{FIGURE 2 Improvements in WOMAC Index Up to 52 Weeks}

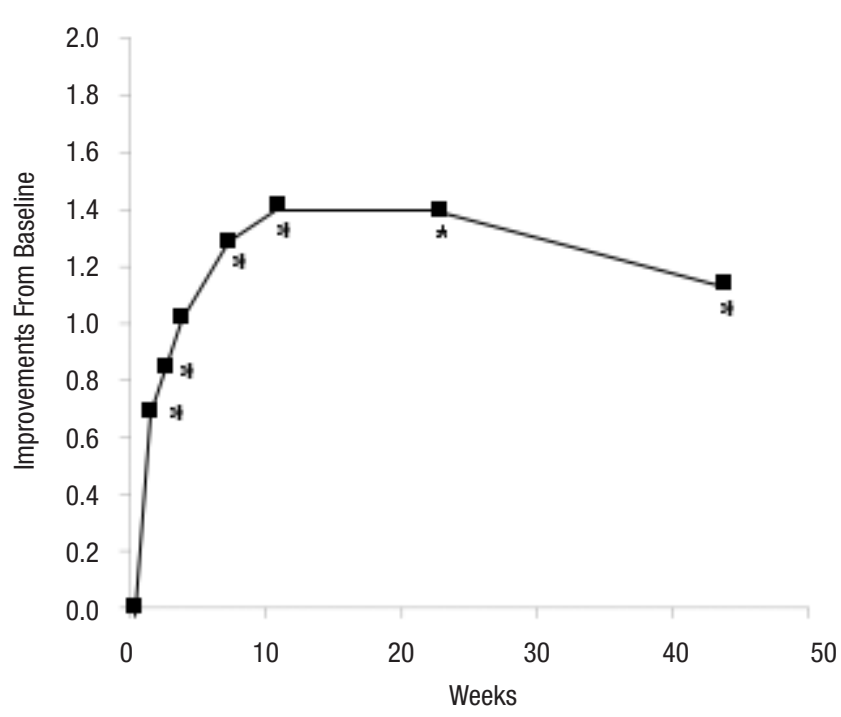

Improvements from baseline (week 0) in scores for the WOMAC index question A1 (pain while walking on a flat surface) with hylan G-F 20 at weeks 1, 2, 4, and $8(n=70), 12(n=67), 26(n=66)$, and $52(n=51)$. Asterisks indicate significant improvements from baseline $(P<.001)$.

Improvements from baseline (week 0) in scores for the Western Ontario and McMaster Universities Osteoarthritis index question A1 (pain while walking on a flat surface) at various time points in a prospective, open-label study to assess a second course of hylan G-F 20 in patients with osteoarthritis of the knee. Adapted with permission from Waddell et al..$^{50}$

pain. Sixty-nine percent (64/93) of knees treated with hylan G-F 20, including 74\% (14/19) of knees with severe OA, did not require TKR during the 2.5-year average follow-up. ${ }^{78}$ In a separate study, 59\% (19/46) of knees treated with hylan G-F 20 did not progress to TKR during the 30-month follow-up. ${ }^{79}$

Waddell and Bricker performed a 6-year retrospective data review of 1,187 knees treated with intra-articular hylan G-F 20 in 863 TKR candidates (100\% grade IV OA of the knee) who underwent 3 weekly intra-articular hylan G-F 20 injections. ${ }^{80}$ Of the knees treated with hylan G-F 20, 45\% and 14\% received 2 and 3 courses of therapy, respectively; fewer patients received $4(4 \%)$ and $5(1.1 \%)$ courses of therapy. The mean age was 67.5 years for patients who did not undergo TKR and 66.8 years for those who underwent TKR. The overall incidence of TKR in this population was $19.0 \%(\mathrm{n}=225)$. The incidence of TKR was highest in patients aged 60 to 69 years (35.7\%); the lowest incidence of TKR was in patients younger than 50 years $(7.1 \%)$ and older than 80 years (8.4\%). Age was the only significant covariate influencing the odds of TKR $(P=0.0002)$. 


\begin{tabular}{l|c}
\hline TABLE 8 & $\begin{array}{l}\text { Most Frequently Reported Adverse } \\
\text { Events Associated With Visco- } \\
\text { supplementation in 4,235 Patients }\end{array}$ \\
\hline Adverse Event & Local Treatment Related, $\mathbf{n}(\%)$ \\
\hline Joint effusion & $91(2.14)$ \\
\hline Joint swelling & $48(1.13)$ \\
\hline Arthralgia & $42(0.99)$ \\
\hline Joint warmth & $23(0.54)$ \\
\hline Injection site erythema & $13(0.31)$ \\
\hline All injection site reactions & $217(5.12)$ \\
\hline
\end{tabular}

These adverse events in aggregate may be quite high as many are related to the same injection-site reaction.

\begin{tabular}{|c|c|c|}
\hline BLE 9 & $\begin{array}{l}\text { ender } \\
\text { arthrit } \\
\text { Severi } \\
\text { ic Moc } \\
\text { d Care }\end{array}$ & $\begin{array}{l}\text { ion } \\
\text { nee } \\
\text { rmaco- } \\
\text { nts in a }\end{array}$ \\
\hline & & \\
\hline Disease Severity (\%) & $35-64$ & Older Than 64 \\
\hline Mild* & 40 & 20 \\
\hline Moderate $\dagger$ & 40 & 50 \\
\hline Severe $\neq$ & 20 & 30 \\
\hline $\begin{array}{l}\text { * Discomfort but rare } \mathrm{fu} \\
\text { † Some functional limit } \\
\text { analgesic or nonsteroi } \\
\text { † Poor mobility and nea } \\
\text { treatment. } \\
\text { Adapted with permissior }\end{array}$ & $\begin{array}{l}\text { tation; } e p \\
\text { duced } m e \\
\text { ammator } \\
\text { t pain; } f r \\
\text { tell et al. }\end{array}$ & $\begin{array}{l}\text { ares requiring cons } \\
\text { ual flares requiring }\end{array}$ \\
\hline
\end{tabular}

The time to TKR was 638 days, or 1.8 years per survival analysis. Therefore, in TKR candidates, symptomatic relief from hylan G-F 20 therapy for OA of the knee can delay the need for surgery. No data are available on the effect of other HA products on TKR.

The ability to delay TKR would be advantageous for patients in whom TKR is not medically appropriate or for patients who fear or do not prefer surgical intervention. Delay of TKR would also decrease the need for revision arthroplasties, which are associated with greater risk of complications than index procedures. Because TKRs are costly, can carry serious risks, and may need revision in younger patients, treatment that would delay last-resort surgery would be valuable.

\section{Tolerability of Viscosupplementation}

Local adverse events with viscosupplementation are typical of those observed with other intra-articular injections, including corticosteroids and saline. In a large study of hylan G-F 20, local treatment-related adverse events occurred in $4.2 \%$ of 4,253 patients and $2.4 \%$ of 12,600 injections. $^{70}$ Results of the analysis of synovial fluid obtained from reactive knees after viscosupplementation showed that local adverse events were noninfectious, inflammatory, noncrystalline induced, and nonallergic. Most adverse events were mild to moderate and included joint effusion and swelling, arthralgia, joint warmth, and injection site erythema (Table 8).$^{70} \mathrm{~A}$ higher, statistically significant incidence of injection-site pain was reported in an earlier, smaller, randomized controlled study of intra-articular hyaluronate in patients with OA: $23 \%$ versus $13 \%$ with placebo $(P<0.01) .{ }^{81}$ Rare incidences of gout, anaphylactoid reactions, and severe acute inflammatory reactions have been reported with viscosupplementation. ${ }^{81}$

\section{Cost Implications of Viscosupplementation in the Managed Care Setting}

The cost-effectiveness and cost utility of viscosupplementation via HA injections (hylan G-F 20) were measured using prospective data from a 1-year randomized, controlled, open-label Canadian trial by Torrance et al. ${ }^{82}$ In this trial, 225 patients were randomly assigned to "appropriate care with hylan G-F 20" $(\mathrm{AC}+\mathrm{H})$ or "appropriate care without hylan G-F 20" (AC), which included intra-articular glucocorticoids, and completed a number of outcomes questionnaires, including the WOMAC and the Health Utilities Index Mark 3. Over the year, the AC+H group incurred higher costs (Canadian $\$ 2,125$ vs. $\$ 1,415 ; P<0.05$ ), improved more significantly (69\% vs. $40 \% ; P=0.001$ ), and experienced increased quality-adjusted life-years (QALYs, which means years of perfect health; 0.071; $P<0.05)$ than the AC group. The incremental cost-effectiveness ratio (the ratio of change in costs) was $\$ 2,505$ per patient improved. The incremental cost-utility ratio (a function of the incremental cumulative costs divided by incremental cumulative effects over the year of the study) was Canadian $\$ 10,000$ per QALY gained. Since the cost-utility ratio is below the suggested Canadian adoption threshold, the investigators stated that their results provide strong evidence for HA treatment in patients with OA of the knee and in settings similar to those studied in the trial.

To illustrate the current cost of treating $\mathrm{OA}$ of the knee and to demonstrate potential savings associated with viscosupplementation in a managed care setting, Waddell et al. developed a pharmacoeconomic model with inputs obtained from peer-reviewed medical literature, clinical trial data, clinical expert opinion, and claims data. ${ }^{83}$ A hypothetical cohort of subjects (mild, moderate, severe OA of the knee; Table 9) was followed up over a 3-year period. Analysis was conducted from the perspective of a managed care plan with a large Medicare population.

The 3-year savings to the plan associated with adding 1 or more courses of hylan G-F 20 therapy to the standard treatment 


\begin{tabular}{|c|c|c|c|c|}
\hline Description & Year 1 & Year 2 & Year 3 & Overall \\
\hline Base-case treatment costs $(\$)$ & $15,455,330$ & $16,569,839$ & $23,834,031$ & $55,859,200$ \\
\hline $\begin{array}{l}\text { Osteoarthritis of the knee treatment costs } \\
\text { with G-F } 20 \text { added (\$) }\end{array}$ & $10,414,476$ & $14,927,606$ & $21,706,346$ & $47,048,428$ \\
\hline Annual savings (\$) & $5,040,854$ & $1,642,232$ & $2,127,685$ & $8,810,771$ \\
\hline Decreases (\%) & 33 & 10 & 9 & 16 \\
\hline Average annual savings over 3 years $(\$)$ & & & & $2,936,924$ \\
\hline $\begin{array}{l}\text { Total average savings per patient with } \\
\text { osteoarthritis receiving G-F } 20 \text { over } \\
3 \text { years (\$) }\end{array}$ & & & & 4,706 \\
\hline
\end{tabular}

\section{TABLE 11 TKRs Avoided in a Pharmacoeconomic Model of Patients With Osteoarthritis of the Knee in a Managed Care Setting}

\begin{tabular}{|c|c|c|c|c|}
\hline Description & Year 1 & Year 2 & Year 3 & Overall \\
\hline $\begin{array}{l}\text { Cases without HA: number } \\
\text { of TKRs }\end{array}$ & 290 & 409 & 808 & 1507 \\
\hline $\begin{array}{l}\text { Cases with HA: number of } \\
\text { TKRs }\end{array}$ & 0 & 290 & 408 & 699 \\
\hline $\begin{array}{l}\text { Total number of TKRs } \\
\text { avoided with G-F } 20\end{array}$ & 290 & 119 & 399 & 808 \\
\hline
\end{tabular}

Adapted with permission from Waddell et al. ${ }^{83} \mathrm{HA}=$ hyaluronic acid; TKR=total knee replacement.

pathway for OA of the knee was $\$ 8,810,771$ (Table 10). The total savings per patient with OA receiving hylan G-F 20 was $\$ 4,706$. These savings were based on the assumption that 808 TKRs were avoided (Table 11). This estimate presumed that patients would not opt for arthroplasty as long as their knee pain was being relieved satisfactorily by nonsurgical means (a presumption supported by the 3 studies cited above). The model was therefore highly sensitive to the durability of the analgesic effect of hylan G-F 20; increasing and decreasing durability within a reasonable range resulted in 3-year savings of $\$ 9,131,879$ and $\$ 2,012,082$, respectively. ${ }^{83}$

This same study also looked at managed care plans with no or few Medicare-aged enrollees. When the analysis was rerun to determine cost savings in a younger (i.e., younger than 65 years) population, the population of patients with $\mathrm{OA}$ of the knee dropped $66 \%$ to 1,297 . The number of patients receiving hylan G-F 20 also dropped 76\% from 1,872 to 441. Using this model, the total savings decreased $80 \%$-from $\$ 8.8$ million to $\$ 1.7$ million. However, the savings per patient with OA of the knee receiving G-F 20 therapy did not decline to the same level (from $\$ 4,706$ to $\$ 3,920$, down $16 \%$ ). These results show that managed care plans with no or few Medicare-aged enrollees still can achieve considerable savings on a per-patient basis. While the removal of aged enrollees reduced the overall savings, the savings that were achieved remained positive and considerable among patients treated with hylan G-F $20 .{ }^{83}$

Figure 3 highlights some significant differences among the hyaluronic products that are of interest to those in the managed care field. For example, these injections are administered in a course of 3 or 5 weekly injections costing $\$ 100$ to $\$ 200$ per injection, not including the cost of the physician office visit. Also, because the numbers of injections required for a course of treatment are different-and therefore the number of office visits vary accordingly - the total cost of HA therapies varies 


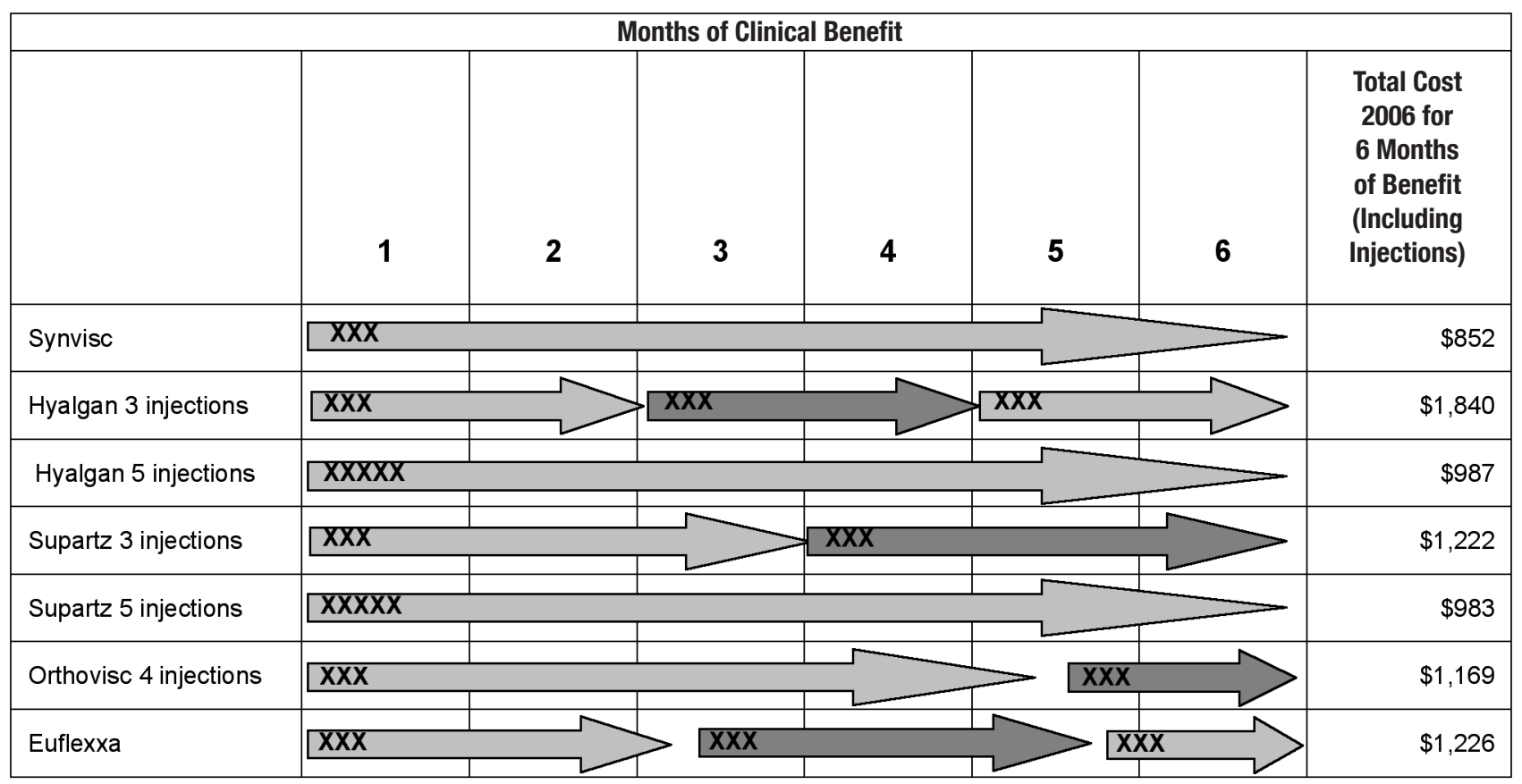

Assumptions: Wholesale acquisition costs for viscosupplementation products as published in November 2006 Red Book, \$70/arthrocentesis, \$53/office visit. Orthovisc is now approved for a series of 3 injections. Costs associated with 6 months of benefit are not yet available.

Note:

Synvisc (hylan G-F 20) is a registered trademark of Genzyme Biosurgery.

Hyalgan (sodium hyaluronate) is a registered trademark of Fidia Farmacautici S.p.A.

Supartz (sodium hyaluronate) is a registered trademark of Seikagaku Corporation.

Orthovisc (high molecular weight hyaluronan) is a registered trademark of Anika Therapeutis, Inc.

Euflexxa (1\% sodium hyaluronate) is a trademark of Ferring Pharmaceuticals Inc.

Source:

Federal Register. Vol 70, No. 223, Monday, November 21, 2005.

among the different agents. Proven FDA-approved durations vary among the different products. For example, 3 injections of sodium hyaluronate are an option. However, since the duration of effect is shorter than with 5 injections, a patient may require more total injections in a fixed period for symptom relief. Therefore, the total cost for 6 months of benefit, which may require multiple courses of therapy, can range from $\$ 852$ to $\$ 1,840$, depending on which product is used. Such costs were calculated using the wholesale acquisition costs for the products, the cost of arthrocentesis, and the cost of office visits.

\section{Conclusions}

OA represents an advanced stage of an active, progressive disease process. Medical research has led to the understanding that $\mathrm{OA}$ is the endpoint of a continued progression in tissue degradation resulting in loss of cartilage structure and function. Relief of pain and preservation of joint tissue must evolve to encompass treatments that interfere with the induction of cartilage-degrading mechanisms that follow acute or chronic injury, restore normal cartilage and joint homeostasis, and arrest the progression of disease. ${ }^{84}$ Optimal treatments of the future should also reverse, whenever possible, existing damage and restore normal cartilage structure and function.

HA preparations are indicated for the treatment of pain in patients with $\mathrm{OA}$ of the knee whose condition has failed to adequately respond to conservative nonpharmacologic therapy and to traditional analgesics and in those for whom NSAIDs, COX-2 inhibitors, and intra-articular glucocorticoids are either contraindicated or ineffective. Clinicians in the managed care 
setting should consider using viscosupplementation in patients (1) who have persistent pain despite the use of conservative therapy, (2) who have compromised GI function or at risk of GI bleeding due to the adverse events of NSAIDs, (3) who are taking concomitant anticoagulant therapy for any condition, (4) who have cardiovascular or renal risk factors precluding use of COX-2 inhibitors, and (5) for whom surgery is not appropriate.

Results of studies are published or studies are under way to test the theory that HA therapy will improve symptoms and function in other joints, such as the shoulder, hand, hip, temporomandibular joint, spine, and ankle. ${ }^{85}$ Further study should be conducted with larger numbers of patients to help identify a subgroup of patients with $\mathrm{OA}$ in whom HA treatments may have even greater effects. ${ }^{11}$ Additional research should also concentrate on assessing the risks and benefits of extended treatments, because limited data are available concerning the effectiveness of multiple courses of therapy.

Considering its prevalence and economic effect, OA is an important public health issue. OA is the leading cause of disability in our country. As the population ages, the socioeconomic costs of this disease will dramatically increase. In light of systemic side effects of therapies for OA of the knee, patients may prefer local therapy for their local joint disease. Viscosupplementation is one treatment with proven efficacy in $\mathrm{OA}$ of the knee. Its use in the managed care arena may improve patients' symptoms and thereby reduce hospitalizations and improve efficient use of clinical resources.

\section{REFERENCES}

1. Beers MH, Porter RS, Jones TV, Kaplan JL, Berkwits M, eds. Osteoarthritis. The Merck Manual of Diagnosis and Therapy. 18th ed. Whitehouse Station, NJ: Merck Research Laboratories; 2006:294-97.

2. Creamer P, Lethbridge-Cejku M, Hochberg MC. Factors associated with functional impairment in symptomatic knee osteoarthritis. Rheumatology (Oxford). 2000;39:490-96.

3. Gabriel SE, Crowson CS, O'Fallon WM. Costs of osteoarthritis: estimates from a geographically defined population. J Rheumatol. 1995;22(suppl 43):23-25.

4. Lanes SF, Lanza LL, Radensky PW, et al. Resource utilization and cost of care for rheumatoid arthritis and osteoarthritis in a managed care setting. Arthritis Rheum. 1997;40:1475-81.

5. Mandelbaum B, Waddell D. Etiology and pathophysiology of osteoarthritis. Orthopedics. 2005;28(suppl):S207-S214.

6. Woolf CJ. Pain: moving from symptom control toward mechanism-specific pharmacologic management. Ann Intern Med. 2004;140:441-51.

7. Moskowitz RW, Kelly MA, Lewallen DG. Understanding osteoarthritis of the knee-causes and effects. Am J Orthop. February 2004;33(2 suppl):5-9.

8. Kaiyama J, Uzuki M. Alteration of hyaluronic acid property in synovial fluid of patient with osteoarthritis. J Iwate Med Assoc. 2006;58:9-21.

9. Dillon CF, Rasch EK, Gu Q, Hirsch R. Prevalence of knee osteoarthritis in the United States: arthritis data from the Third National Health and Nutrition Examination Survey 1991-94. J Rheumatol. 2006;33:2271-79.
10. American Academy of Orthopaedic Surgeons. The impact of osteoarthritis of the knee. April 2003. Available at: http://www.orthoinfo.org/fact/printer_ page.cfm?topcategory=knee\&Thread_ID=419. Accessed December 17, 2006.

11. American Academy of Orthopaedic Surgeons. Osteoarthritis of the knee: state of the condition. Osteoarthritis of the Knee: A Compendium of Evidence-based Information and Resources. Rosemont, IL: American Academy of Orthopaedic Surgeons; 2004. Available at: http://www.aaos.org/Research/documents/ OAinfo_knee_state.pdf. Accessed December 25, 2006.

12. Fan Z, Tardif G, Boileau C, et al. Identification in human osteoarthritic chondrocytes of proteins binding to the novel regulatory site AGRE in the human matrix metalloprotease 13 proximal promoter. Arthritis Rheum. 2006;54:2471-80

13. Jinks C, Jordan K, Croft P. Disabling knee pain—another consequence of obesity: results from a prospective cohort study. BMC Public Health. 2006;6:258

14. Zhang Y, Xu L, Nevitt MC, et al. Comparison of the prevalence of knee osteoarthritis between the elderly Chinese population in Beijing and Whites in the United States: the Beijing osteoarthritis study. Arthritis Rheum 2001;44:2065-71.

15. Felson DT, Naimark A, Anderson J, et al. The prevalence of knee osteoarthritis in the elderly: the Framingham Osteoarthritis Study. Arthritis Rheum. 1987;30:914-18.

16. Lawrence RC, Hochberg MC, Kelsey JL, et al. Estimates of the prevalence of selected arthritic and musculoskeletal diseases in the United States. J Rheumatol. 1989;16:427-41.

17. Felson DT, Lawrence RC, Dieppe PA, et al. Osteoarthritis: new insights. Part 1: the disease and its risk factors. Ann Intern Med. 2000;133:635-46.

18. Oliveria SA, Felson DT, Klein RA, Reed JI, Walker AM. Estrogen replacement therapy and the development of osteoarthritis. Epidemiology. 1996;7:415-19.

19. Sowers MF. Epidemiology of risk factors for osteoarthritis: systemic factors. Curr Opin Rheumatol. 2001;13:447-51.

20. Holmberg S, Thelin A, Thelin N. Is there an increased risk of knee osteoarthritis among farmers? A population-based case-control study. Int Arch Occup Environ Health. 2004;77:345-50.

21. Thelin N, Holmberg S, Thelin A. Knee injuries account for the sports-related increased risk of knee osteoarthritis. Scand J Med Sci Sports. 2006;16:329-33.

22. Cooper C, Dennison C. Osteoarthritis. In: Brandt KD, Doherty M, Lohmander LS, eds. Osteoarthritis. Oxford, NY: Oxford University Press; 1998:237-49.

23. Hannan MT, Felson DT, Pincus T. Analysis of the discordance between radiographic changes and knee pain in osteoarthritis of the knee. J Rheumatol. 2000;27(6):1513-17.

24. Altman R, Asch E, Bloch D, et al. Development of criteria for the classification and reporting of osteoarthritis. Classification of osteoarthritis of the knee. Diagnostic and Therapeutic Criteria Committee of the American Rheumatism Association. Arthritis Rheum. 1986;29:1039-49.

25. Snibbe JC, Gambardella RA. Treatment options for osteoarthritis. Orthopedics. 2005;28(suppl):S215-S220.

26. American College of Rheumatology. Recommendations for the medical management of osteoarthritis of the hip and knee: 2000 update. American College of Rheumatology Subcommittee on Osteoarthritis Guidelines. Arthritis Rheum. 2000;43:1905-15.

27. Petrella RJ, DiSilvestro MD, Hildebrand C. Effects of hyaluronate sodium on pain and physical functioning in osteoarthritis of the knee. Arch Intern Med. 2002;162:292-98. 
28. McClean G. The analgesic efficacy of topical capsaicin is enhanced by glyceryl trinitrate in painful osteoarthritis: a randomized, double-blind, placebo controlled study. Eur J Pain. 2000;4(4):355-60.

29. Gammaitoni AR, Galer BS, Onawola R, Jensen MP, Argoff CE. Lidocaine patch $5 \%$ and its positive impact on pain qualities in osteoarthritis: results of a pilot 2-week, open-label study using the Neuropathic Pain Scale. Curr Med Res Opin. 2005;20(suppl 2):S13-S19.

30. Burch F, Codding C, Patel N, Sheldon E. Lidocaine patch 5\% improves pain, stiffness, and physical function in osteoarthritis pain patients. A prospective, multicenter, open-label effectiveness trial. Osteoarthritis Cartilage. 2004;12(3):252-55.

31. Towheed TE, Maxwell L, Judd MG, et al. Acetaminophen for osteoarthritis. Cochrane Database Syst Rev. 2006;25(1):CD004257.

32. Zhang W, Jones A, Doherty M. Does paracetamol (acetaminophen) reduce the pain of osteoarthritis?: a meta-analysis of randomized controlled trials. Ann Rheum Dis. 2004;63:901-07.

33. Wolfe F, Zhao S, Lane N. Preference for nonsteroidal anti-inflammatory drugs over acetaminophen by rheumatic disease patients: a survey of 1,799 patients with osteoarthritis, rheumatoid arthritis, and fibromyalgia. Arthritis Rheum. 2000;43:378-85.

34. Pincus T, Swearingen C, Cummins P, Callahan LF. Preference for nonsteroidal anti-inflammatory drugs versus acetaminophen and concomitant use of both types of drugs in patients with osteo arthritis. J Rheumatol. 2000;27:1020-27.

35. Bond GR, Hite LK. Population-based incidence and outcome of acetaminophen poisoning by type of ingestion. Acad Emerg Med. 1999;6(11): $1115-120$

36. Larson A, Polson J, Fontana RJ, et al. Acetaminophen-induced acute liver failure: results of a United States multicenter, prospective study. Hepatology. 2005;42:1364-72.

37. Watkins PB, Kaplowitz N, Slattery JT, et al. Aminotransferase elevations in healthy adults receiving 4 grams of acetaminophen daily. JAMA. 2006;296:87-93

38. Hylek EM, Heiman H, Skates SJ, Sheehan MA, Singer DE. Acetaminophen and other risk factors for excessive warfarin anticoagulation. JAMA.

1998;279:657-62.

39. Temple AR, Benson GD, Zinsenheim JR, Schweinle JE. Multicenter, randomized, double-blind, active-controlled, parallel-group trial of the long-term (6-12 months) safety of acetaminophen in adult patients with osteoarthritis. Clin Ther. 2006;28:222-35.

40. Bjordal JM, Ljunggren AE, Klovning A, Slordal L. Non-steroidal antiinflammatory drugs, including cyclo-oxygenase-2 inhibitors, in osteoarthritic knee pain: meta-analysis of randomized placebo controlled trials. BMJ. 2004:329:1317-22

41. Buffum M, Buffum JC. Nonsteroidal anti-inflammatory drugs in the elderly. Pain Manag Nurs. 2000;1:40-50.

42. Geba GP, Weaver AL, Polis AB, et al. Efficacy of rofecoxib, celecoxib, and acetaminophen in osteoarthritis of the knee. JAMA. 2002;287:64-71.

43. Hawkey CJ, Laine L, Simon T, et al. Comparison of the effect of rofecoxib (a cyclooxygenase 2 inhibitor), ibuprofen, and placebo on the gastroduodenal mucosa of patients with osteoarthritis: a randomized, double-blind, placebocontrolled trial. The Rofecoxib Osteoarthritis Endoscopy Multinational Study Group. Arthritis Rheum. 2000;43:370-77.

44. US Food and Drug Administration. COX-2 Selective (includes Bextra, Celebrex, and Vioxx) and Non-Selective Non-Steroidal Anti-Inflammatory Drugs (NSAIDs) April 6, 2005. Available at: http://www.fda.gov/cder/drug/ infopage/COX2/default.htm\#COX2. Accessed December 17, 2006.
45. Dalgin P, TPS-OA Study Group. Comparison of tramadol and ibuprofen for the chronic pain of osteoarthritis [abstract]. Arthritis Rheum. 1997;40(suppl 9): S86.

46. Clegg DO, Reda DJ, Harris CL, et al. Glucosamine, chondroitin sulfate, and the two in combination for painful knee osteoarthritis. N Engl J Med. 2006;354:795-808.

47. Bellamy N, Campbell J, Robinson V, et al. Intraarticular corticosteroid for treatment of osteoarthritis of the knee. Cochrane Database Syst Rev. 2006;(2): CD005328.

48. Schumacher HR, Chen LX. Injectable corticosteroids in treatment of arthritis of the knee. Am J Med. 2005;118:1208-14.

49. Kurtz S, Mowat F, Ong K, et al. Prevalence of primary and revision total hip and knee arthroplasty in the United States from 1990 through 2002.

J Bone Joint Surg. 2005;87:1487-97.

50. Waddell DD, Cefalu CA, Bricker DC. A second course of hylan G-F 20 for the treatment of osteoarthritic knee pain: 12-month patient follow-up. J Knee Surg. 2005;18:7-15.

51. Bellamy N, Campbell J, Robinson V, Gee T, Bourne R, Wells G. Viscosupplementation for the treatment of osteoarthritis of the knee. Cochrane Database Syst Rev. 2006;(2):CD005321.

52. Bagga H, Burkhardt D, Sambrook P, March L. Longterm effects of intraarticular hyaluronan on synovial fluid in osteoarthritis of the knee. J Rheumatol. 2006;33:946-50,

53. Marshall KW. Viscosupplementation for osteoarthritis: current status, unresolved issues and future directions. J Rheumatol. 1998;25:2056-58.

54. Euflexxa [prescribing information]. Suffern, NY: Ferring Pharmaceuticals, Inc.; 2006 .

55. Synvisc [prescribing information]. Ridgefield, NJ: Genzyme Corp; 2004

56. Orthovisc [prescribing information]. Woburn, MA: Anika Therapeutics, Inc; 2005.

57. Hyalgan [prescribing information]. New York, NY: Sanofi-Synthelabo Inc; 2001.

58. Supartz [prescribing information]. Tokyo, Japan: Seikagaku Corp; 2006.

59. Wobig M, Bach G, Beks P, et al. The role of elastoviscosity in the efficacy of viscosupplementation for osteoarthritis of the knee: a comparison of hylan G-F 20 and a lower-molecular-weight hyaluronan. Clin Ther. 1999;21:1549-62.

60. Wang CT, Lin J, Chang CJ, Lin YT, Hou SM. Therapeutic effects of hyaluronic acid on osteoarthritis of the knee: a meta-analysis of randomized controlled trials. J Bone Joint Surg Am. 2004;86-A:538-45.

61. Pozo MA, Balazs EA, Belmonte C. Reduction of sensory responses to passive movements of inflamed knee joints by hylan, a hyaluronan derivative. Exp Brain Res. 1997;116:3-9.

62. Gomis A, Pawlak M, Balazs EA, Schmidt RF, Belmonte C. Effects of different molecular weight elastoviscous hyaluronan solutions on articular nociceptive afferents. Arthritis Rheum. 2004;50:314-26.

63. Sato H, Takahashi T, Ide H, et al. Antioxidant activity of synovial fluid, hyaluronic acid, and two subcomponents of hyaluronic acid. Synovial fluid scavenging effect is enhanced in rheumatoid arthritis patients. Arthritis Rheum. 1988;31:63-71.

64. Forrester JV, Balazs EA. Inhibition of phagocytosis by high molecular weight hyaluronate. Immunology. 1980;40:435-46.

65. Tobetto K, Nakai K, Akatsuka M, Yasui T, Ando T, Hirano S. Inhibitory effects of hyaluronan on neutrophil-mediated cartilage degradation. Connect Tissue Res. 1993;29:181-90. 
66. Evanich JD, Evanich CJ, Wright MB, Rydlewicz JA. Efficacy of intraarticular hyaluronic acid injections in knee osteoarthritis. Clin Orthop Relat Res. 2001;(390):173-81.

67. Vad VB, Bhat AL, Sculco TP, Wickiewicz TL. Management of knee osteoarthritis: knee lavage combined with hylan versus hylan alone. Arch Phys Rehabil. 2003;84:634-37.

68. Altman RD, Moskowitz R. Intraarticular sodium hyaluronate (Hyalgan) in the treatment of patients with osteoarthritis of the knee: a randomized clinical trial. Hyalgan Study Group. J Rheumatol. 1998;25:2203-12.

69. Kirwan JR, Rankin E. Intra-articular therapy in osteoarthritis. Baillieres Clin Rheumatol. 1997;11:769-94.

70. Kemper F, Gebhardt U, Meng T, Murray C. Tolerability and short-term effectiveness of hylan G-F 20 in 4253 patients with osteoarthritis of the knee in clinical practice. Curr Med Res Opin. 2005;21:1261-1269.

71. Lussier A, Cividino AA, McFarlane CA, Olszynski WP, Potashner WJ, De Medicis R. Viscosupplementation with hylan for the treatment of osteoarthritis: findings from clinical practice in Canada. J Rheumatol. 1996;23:1579-85.

72. American Academy of Orthopaedic Surgeons. Viscosupplementation treatment for osteoarthritis. November 2000. Available at: http://www.orthoinfo. org/ fact/thr_report.cfm?Thread_ID=245\&topcategory=Arthritis. Accessed December 25, 2006.

73. Raman R, Dutta A, Day N, Shaw CJ, Johnson GV. The efficacy of hylan G-F 20 and sodium hyaluronate in the treatment of osteoarthritis of the knee: a prospective randomized double-blinded clinical trial. Osteoarthritis Cartilage. 2006;14(suppl B):S162.

74. Lohmander LS, Dalen N, Englund G, et al. Intra-articular hyaluronan injections in the treatment of osteoarthritis of the knee: a randomized, doubleblind, placebo controlled multicentre trial. Ann Rheum Dis. 1996;55:424-31.

75. Wobig M, Dickhut A, Maier R, Vetter G. Viscosupplementation with hylan G-F 20: a 26-week controlled trial of efficacy and safety in the osteoarthritic knee. Clin Ther. 1998;20:410-23.
76. Pagnano M, Westrich G. Successful nonoperative management of chronic osteoarthritis pain of the knee: safety and efficacy of retreatment with intraarticular hyaluronans. Osteoarthritis Cartilage. 2005;13:751-61.

77. Karatosun V, Unver B, Gocen Z, Sen A, Gunal I. Intra-articular hyaluronic acid compared with progressive knee exercises in osteoarthritis of the knee: a prospective randomized trial with long-term follow-up. Rheumatol Int. 2006;26:277-84.

78. Marshall KW. European Federation of National Associations of Orthopedics and Traumatology. Brussels Congress. June 1999, Abstracts. J Bone Joint Surg Br. 1999;81(suppl 2):S123-S269.

79. Bell M. 4th World Congress of the Osteoarthritis Research Society International (OARSI). Vienna, Austria, September 16-19, 1999. Abstracts. Osteoarthritis Cartilage. 1999; 7(suppl A):S1-S38.

80. Waddell DD, Bricker DC. Total knee replacement delayed during six years of hylan G-F 20 use in orthopedic practice. J Manag Care Pharm. 2007;13(2):113-21. Available at: http://www.amcp.org/data/jmcp/pl13-21/pdf. Accessed April 23, 2007.

81. Hamburger MI, Lakhanpal S, Mooar PA, Oster D. Intra-articular hyaluronans: a review of product-specific safety profiles. Semin Arthritis Rheum. 2003;32(5):296-309.

82. Torrance GW, Raynauld JP, Walker V, et al.; Canadian Knee OA Study Group. A prospective, randomized, pragmatic, health outcomes trial evaluating the incorporation of hylan G-F 20 into the treatment paradigm for patients with knee osteoarthritis (part 2 of 2): economic results. Osteoarthritis Cartilage. 2002;10:518-27

83. Waddell D, Rein A, Panarites C, Coleman PM, Weiss C. Cost impli-cations of introducing an alternative treatment for patients with osteoarthritis of the knee in a managed care setting. Am J Manag Care. 2001;7:981-91.

84. Baker CL, Ferguson CM. Future treatment of osteoarthritis. Orthopedics. 2005;28(2 suppl):S227-S234.

85. Kelly MA, Moskowitz RW, Lieberman JR. Hyaluronan therapy: looking toward the future. Am J Orthop. 2004;33(2 suppl):23-28. 


\section{Viscosupplementation: Managed Care Issues for Osteoarthritis of the Knee}

This activity may be completed online* or by indicating the correct answer on the Posttest Answers form and faxing or mailing that and the Program Evaluation form to Postgraduate Institute for Medicine (see page S21 for instructions).

1. In persons younger than 40 years of age, most osteoarthritis a. is in men and results from obesity.

b. is in men and results from trauma.

c. is in women and relates to menopause.

d. is in women and relates to genetic predisposition.

2. Cartilage is made up mostly of

a. hyaluronic acid.

b. matrix proteoglycans.

c. collagen.

d. water.

3. Which statement about the pathophysiology of osteoarthritis is not true?

a. It is a disease that is strictly caused by the wear and tear of aging.

b. Degenerative changes are seen in non-weight-bearing surfaces as well as in weight-bearing joints.

c. The water content in cartilage of an aging joint does not change significantly.

d. The subchondral bone changes associated with osteoarthritis are not seen in an aging joint.

4. Evidence shows that regular, moderate use of healthy joints does not increase the risk for osteoarthritis.
a. True
b. False

5. Which statement about acetaminophen is true?

a. It is the most common cause of renal failure.

b. It is the most common cause of liver failure.

c. Studies show that patients with OA prefer acetaminophen over the nonsteroidal anti-inflammatory drugs.

d. It should be used with misoprostol.
6. Which is not true of the hylans?

a. They are synthetic.

b. They are cross-linked hyaluronan chains.

c. Their average molecular weight is 6 million $\mathrm{d}$.

d. They form a randomized coil in physiologic solvents.

7. Hyaluronic acid supplementation can modulate leukocyte function, including macrophage phagocytosis, a process that is more pronounced in

a. higher-molecular-weight hyaluronic acid preparations.

b. more severe osteoarthritis.

c. older patients.

d. All of the above

8. Patients with a complete collapse of joint space or bone loss with intra-articular hyaluronic acid may benefit the most from viscosupplementation.

a. True

9. Which of the following hyaluronates has the highest molecular weight?

a. Sodium hyaluronate

b. Hylan G-F 20

c. Hyaluronic acid found in human synovial fluid

d. High-molecular-weight hyaluronan

10. In a recent prospective, randomized trial comparing hylan G-F 20 and sodium hyaluronate in patients with osteoarthritis of the knee, the cost of the agents was comparable, but the total treatment cost was 23\% more in the hyaluronate group because of

a. poor efficacy.

b. increased number of side effects.

c. more visits to complete the necessary number of injections.

d. All of the above

*To complete this activity ("Viscosupplementation: Managed Care Issues for Osteoarthritis of the Knee)" online, go to www.amcp.org (Learning Center/Online CE), where you will access the posttest and evaluation form. 


\section{Viscosupplementation: Managed Care Issues for Osteoarthritis of the Knee}

If you wish to receive acknowledgment for completing this activity, please complete the posttest and Program Evaluation form (and Verification of Participation form, if applicable) and fax to (303) 790-4876 or mail to Postgraduate Institute for Medicine, 367 Inverness Pkwy., Suite 215, Attention: Records Dept., Englewood, CO 80112.

\section{Posttest Answers}

\begin{tabular}{|l|l|l|l|l|l|l|l|l|l|}
\hline 1 & 2 & 3 & 4 & 5 & 6 & 7 & 8 & 9 & 10 \\
\hline
\end{tabular}

\section{Request for Credit}

Name Degree

Organization Specialty

Address

City, State, ZIP

Telephone Fax E-mail

\section{Physicians}

I participated in the entire activity and claim 1.25 credits.

I participated in only part of the activity and claim credits.

\section{Pharmacists}

I participated in the entire activity and claim full contact hours.

\section{Nurses}

I participated in the entire activity and claim full contact hours.

\section{Case Managers}

I participated in the entire activity and claim full contact hours.

Please submit Verification of Completion form on page S23. 
PROGRAM EVALUATION

\section{Viscosupplementation: Managed Care Issues for Osteoarthritis of the Knee}

To assist us in evaluating the effectiveness of this activity and to make recommendations for future educational offerings, please take a few minutes to complete this evaluation form. You must complete this evaluation form to receive acknowledgment of participation for this activity. (PIM ID \#4581 ES 29)

Please answer the following questions by circling the appropriate rating:
1 = Strongly Disagree
2 = Disagree
$3=$ Neutral
$4=$ Agree
$5=$ Strongly Agree

\section{Extent to Which Program Activities Met the Identified Purpose}

Provide the latest information on therapeutic options for

$\begin{array}{lllll}1 & 2 & 3 & 4 & 5\end{array}$

osteoarthritis of the knee, including viscosupplementation.

\section{Extent to Which Program Activities Met the Identified Objectives}

After completing this activity, I am now better able to:

- explain the pathophysiologic factors involved in osteoarthritis (OA) of the knee

- describe appropriate treatment for patients with OA of the knee

$\begin{array}{lllll}1 & 2 & 3 & 4 & 5\end{array}$

- discuss benefits of viscosupplementation for management of $\mathrm{OA}$ of the knee as they pertain to the managed care environment

\section{Overall Effectiveness of the Activity}

The content presented:

- Was timely and will influence how I practice

- Enhanced my current knowledge base

- Addressed my most pressing questions

- Provided new ideas or information I expect to use

- Addressed competencies identified by my specialty

- Avoided commercial bias or influence

$\begin{array}{lllll}1 & 2 & 3 & 4 & 5 \\ 1 & 2 & 3 & 4 & 5 \\ 1 & 2 & 3 & 4 & 5 \\ 1 & 2 & 3 & 4 & 5 \\ 1 & 2 & 3 & 4 & 5 \\ 1 & 2 & 3 & 4 & 5\end{array}$

\section{Impact of the Activity}

Name one thing you intend to change in your practice as a result of completing this activity:

Please list any topics you would like to see addressed in future educational activities:

\section{Additional Comments About This Activity:}

\section{Follow-up}

As part of our continuous quality improvement effort, we conduct postactivity follow-up surveys to assess the impact of our educational interventions on professional practice. Please indicate if you would be willing to participate in such a survey:

$\square$ Yes, I would be interested in participating in a follow-up survey.

No, I'm not interested in participating in a follow-up survey. 
VERIFICATION OF COMPLETION

CCMC

(Please print or type all information)

SPONSOR INFORMATION (to be completed by program/activity sponsor)

Excellence in Medical Education

Sponsoring Organization

6 Terry Dr.

Street Address

Newtown, PA 18940-1831

City/State/ZIP Code

\section{$\underline{00096489}$}

Sponsor Code

Liz O'Neill

Contact Person

215.550.8102

Phone Number for Contact Person

PROGRAM/ACTIVITY INFORMATION (to be completed by program/activity sponsor)

2007-Viscosupplementation: Managed Care Issues for Osteoarthritis of the Knee

Program/Activity Title

$12 / 31 / 07$

Program/Activity Date or Date of Completion

9648955690

Approval Number

Clock Hours Attended/Completed

Signature of Individual in Charge of Verifying Attendance/Completion Date of Signature

PARTICIPANT INFORMATION (to be completed by program/activity sponsor)

Name

Street Address
Certificate Number

Daytime Telephone Number

City/State/ZIP Code

To have these clock hours added to your CCMC certification file, please send a copy of this form to CCMC, 300 N. Martingale Rd., Suite 460 Schaumburg, IL 60173. It is best to submit this documentation as activities are completed or at least on an annual basis. This form is for preapproval by CCMC only and will only be added to your certification file with them. If you hold certification from other organizations, you will need to submit verification of attendance/completion according to their requirements.

6 Terry Drive · Newtown, PA $18940 \cdot 215.550 .8102$ 
NOTES 



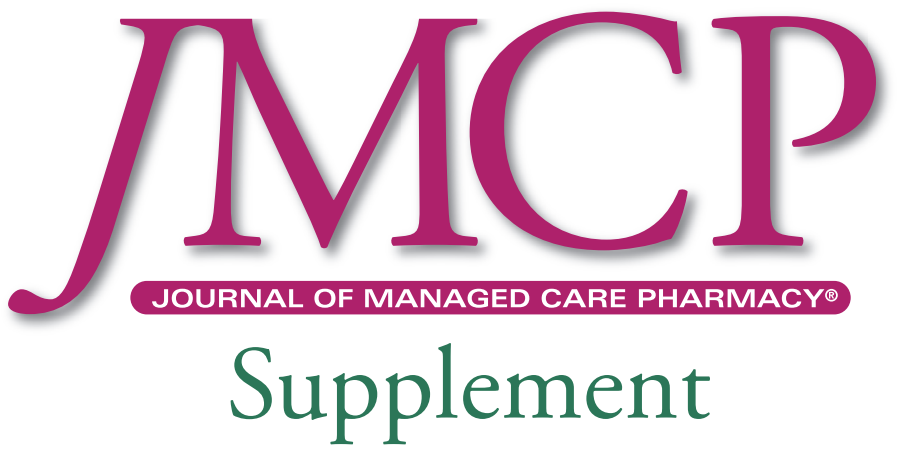

